\title{
Corticothalamic Axons Are Essential for Retinal Ganglion Cell Axon Targeting to the Mouse Dorsal Lateral Geniculate Nucleus
}

\author{
James A. Shanks, ${ }^{1}$ Shinya Ito, ${ }^{2}$ Laura Schaevitz, ${ }^{1,3}$ Jena Yamada, ${ }^{1}$ Bin Chen, ${ }^{1}{ }^{\oplus}$ Alan Litke, ${ }^{2}$ and David A. Feldheim ${ }^{1}$ \\ ${ }^{1}$ Department of Molecular, Cell, and Developmental Biology, University of California, Santa Cruz, California 95064, ${ }^{2}$ Santa Cruz Institute for Particle \\ Physics, University of California, Santa Cruz, Santa Cruz, California 95064, and '3epartment of Biology, Trinity College, Hartford, Connecticut 06106
}

Retinal ganglion cells (RGCs) relay information about the outside world to multiple subcortical targets within the brain. This information is either used to dictate reflexive behaviors or relayed to the visual cortex for further processing. Many subcortical visual nuclei also receive descending inputs from projection neurons in the visual cortex. Most areas receive inputs from layer 5 cortical neurons in the visual cortex but one exception is the dorsal lateral geniculate nucleus (dLGN), which receives layer 6 inputs and is also the only RGC target that sends direct projections to the cortex. Here we ask how visual system development and function changes in mice that develop without a cortex. We find that the development of a cortex is essential for RGC axons to terminate in the dLGN, but is not required for targeting RGC axons to other subcortical nuclei. RGC axons also fail to target to the dLGN in mice that specifically lack cortical layer 6 projections to the dLGN. Finally, we show that when mice develop without a cortex they can still perform a number of vision-dependent tasks.

Key words: axon-targeting; cortex; dLGN; retina; target selection; visual system

\section{Significance Statement}

The dorsal lateral geniculate nucleus (dLGN) is a sensory thalamic relay area that receives feedforward inputs from retinal ganglion cells (RGCs) in the retina, and feed back inputs from layer 6 neurons in the visual cortex. In this study we examined genetically manipulated mice that develop without a cortex or without cortical layer 6 axonal projections, and find that RGC axons fail to project to the dLGN. Other RGC recipient areas, such as the superior colliculus and suprachiasmatic nucleus, are targeted normally. These results provide support for a new mechanism of target selection that may be specific to the thalamus, whereby descending cortical axons provide an activity that promotes feedforward targeting of RGC axons to the dLGN.

\section{Introduction}

The brain detects and processes sensory information using parallel circuits, each of which processes specific aspects of the environment that is then integrated to encode perception and issue appropriate motor commands (Wässle, 2004). Understanding how these circuits form during development is important because a number of developmental disorders are thought to arise

Received Dec. 21, 2015; revised March 23, 2016; accepted March 25, 2016.

Author contributions: J.A.S., S.I., L.S., B.C., A.L., and D.A.F. designed research; J.A.S., S.I., L.S., and J.Y. performed research; B.C. and A.L. contributed unpublished reagents/analytic tools; J.A.S., S.I., L.S., J.Y., A.L., and D.A.F. analyzed data; J.A.S., S.I., and D.A.F. wrote the paper.

This work was supported by the National Institutes of Health Grant R01EY022117 to D.A.F., and a Major Facilities Grant FA1-00617-1 to UCSC.

The authors declare no competing financial interests.

Correspondence should be addressed to Dr David A. Feldheim, Department of Molecular, Cell, and Developmental Biology, University of California, 1156 High Street, Santa Cruz, CA 95064. E-mail: feldheim@biology.ucsc.edu.

DOI:10.1523/JNEUROSCI.4599-15.2016

Copyright $\odot 2016$ the authors $\quad 0270-6474 / 16 / 365252-12 \$ 15.00 / 0$ from the mis-wiring of brain circuitry (Kana et al., 2011; Tye and Bolton, 2013). Furthermore, once elucidated, these same mechanisms used to form connections can be used to rewire connections after injury or disease.

The visual system is an attractive model to study the development of circuit formation. In the mouse visual system the retina transforms the visual scene into $\sim 20$ different channels, each represented by a unique type of retinal ganglion cell (RGC; Masland, 2012). All RGC types send axonal projections to specific subcortical retinal recipient areas that are responsible for executing reflexive and planned behaviors (Dhande and Huberman, 2014). For example, some RGC types fire action potentials in response to changes in luminance (OFF, ON, ON-OFF) or movement in a specific direction (ON-OFF direction selective). These types send axons to the dorsal lateral geniculate nucleus (dLGN) and superior colliculus (SC), referred to as imageforming areas because of their roles in reflexive and planned movements. Intrinsically photosensitive RGCs (ipRGCs) and 
ON direction selective RGCs have axons that project to nuclei involved in specific non-image-forming behaviors. Such regions include the nucleus of the optic tract (NOT) and medial terminal nucleus (MTN) used for eye movements and image stabilization (Dhande et al., 2013), the olivary pretectal nucleus (OPN), which regulates the pupillary light reflex (Chen et al., 2011), and the suprachiasmatic nucleus $(\mathrm{SCN})$, inner geniculate leaflet (IGL), and ventral lateral geniculate nucleus (vLGN), all of which play a role in regulating day/night activity cycles (Cosenza and Moore, 1984; Harrington, 1997; Hattar et al., 2002; Morin et al., 2003). How each RGC type targets a specific nucleus in the brain is not well understood; however, a favorite hypothesis is that target cells express molecules that are selectively recognized by specific RGC types, thereby promoting axon branching and synapse formation (Osterhout et al., 2011, 2015; Sun et al., 2015).

In addition to getting input from RGCs, most retinal recipient areas also receive direct inputs from the visual cortex (Shatz and Rakic, 1981; Schmidt et al., 1993; Seabrook et al., 2013) that feed back to modulate the feedforward projections from the retina (Sillito et al., 2006; Theyel et al., 2010). Layer 5 neurons in the visual cortex project to the SC, vLGN, and OPN, whereas layer 6 neurons innervate the dLGN, the only nucleus that projects directly to the cortex (Schmidt et al., 1993; Erişir et al., 1997; Seabrook et al., 2013). Whether these inputs are required for proper RGC axon targeting during development and target cell receptive field properties is not known.

Here we investigate the developmental and functional changes that occur in the mouse visual system when mice develop without a large portion of their cortex. To do this we examined the retinal projections in $\operatorname{Tra} 2 \beta$ floxed; $E m \times 1$-cre transgenic mice [Tra2 $\beta$ conditional knock-out (cKO)], which lack most of the cortex, including the entire visual cortex (Gorski et al., 2002; Mende et al., 2010; Roberts et al., 2014). We find that $\operatorname{Tra} 2 \beta$ cKO mice have an almost complete loss of RGC axon input into the dLGN, but normally innervate many other RGC targets. RGC axons also fail to completely innervate the dLGN in mice that lack cortical layer 6 projections to the dLGN. This suggests that retinogeniculate target selection requires a cortical axon derived signal that attracts RGC axons to the dLGN.

Layer 5 neurons project to the SC, and we find that the lack of cortical inputs to the SC during development does not dramatically change the visual response properties of SC neurons. Finally, we show that when mice develop without a cortex they are still able to perform a number of vision-dependent tasks.

\section{Materials and Methods}

Mice. Tra $2 \beta$ floxed animals were obtained from Dr Brunhilde Wirth (University of Cologne) and described by Roberts et al. (2014). The Emx1-Cre mouse line (stock 005628) and the Ai9 (RCL-tdT) reporter line (stock 007905) were obtained from The Jackson Laboratory. The Isl2-GFP mouse line is described by Triplett et al. (2014). Tbrl KO animals (Bulfone et al., 1998) were obtained from Dr John Rubenstein (University of California, San Francisco). Mice were genotyped by PCR of tail DNA using the following oligonucleotides: GFP (5'-CCTACGGCGTGCAGTGCTTCAGC-3' and 5'CGGCGAGCTGCACGCTGCGTCCTC-3'); Tra2 $\beta$ (5'AAGGCGTT CTAGATCAAAGTCCAG- ${ }^{\prime}$ and $5^{\prime}$-GTCGACGAGAGGGCACGAGAG GACAATC-3'); Emx1-Cre WT for (5'-GTGCCATCATGAAGGATGC-3') Emx1-Cre for (5'-GTATTTGGTTTAGAGTTTGGC-3') and rev (5'GGGGGACATGAGAGGATGTCAC-3'); Tbr1 KO (5'-GTGGCTAGAG CACGACGGAGAGC-3' and 5'-CTTCTTGACGAGTTCTTCTGA-3'), Tbr1 KO (5'-GGTCGGAGAACCAGTCAGTG-3' and 5'-GGGAGAA GGGAAGACGTAGG-3'); WT (5'-AAGGGAGCTGCAGTGGAGTA-3' and $5^{\prime}$-CCGAAAATCTGTGGGAAGTC-3') and tdTomato (5'-GGCAT TAAAGCAGCGTATCC-3') and 5'-CTGTTCCTGTACGGCATGG-3').
All procedures were performed in accordance with the University of California, Santa Cruz (UCSC) Institutional Animal Care and Use Committee. We found that Tra $2 \beta^{\mathrm{fl} /+} ;$ Emxl-Cre ${ }^{+}, \operatorname{Tra} 2 \beta^{+/+} ;$Emxl-Cre ${ }^{+}, \operatorname{Tra} 2 \beta^{\mathrm{fl} /+}$, or $\operatorname{Tra} 2 \beta^{\mathrm{f} / / \mathrm{fl}}$ (no Cre), had no visible cortical defect. Therefore, we used these as age-matched littermate controls in our experiments. For all Tbr1 KO experiments we used littermate control mice with the genotype Tbr $1^{+/+}$or Tbr ${ }^{ \pm}$. All Tra2 $\beta$ control and mutant animals were in a mixed C57/129 pigmented eye-strain background, whereas Tbrl control and mutant animals were in a Swiss Webster (albino) strain background.

Axon tracing. To anterograde label RGC axons, $\mathrm{P} 0$ mice were anesthetized on ice for $5 \mathrm{~min}$; adult animals were anesthetized using a constant flow of $1 \%$ isoflurane. Approximately $1 \mu \mathrm{l}$ of fluorescently-conjugated cholera toxin subunit B (CT $\beta-488$ or CT $\beta-555$, Life Technologies; 2 $\mathrm{mg} / \mathrm{ml}$ in PBS) was injected into the vitreous of the eye using a pulled glass pipette, previously beveled with a microgrinder (Microdata Instruments MFG-5) using a Picospritzer III (Parker Instruments) set at low pressure and $5 \mathrm{~ms}$ pulse duration. After $2 \mathrm{~d}$, animals were sacrificed and intracardially perfused with PBS containing $4 \%$ paraformaldehyde (PFA). Brains were dissected out and placed in $4 \%$ PFA overnight at $4{ }^{\circ} \mathrm{C}$, then cryoprotected by equilibrating in $30 \%$ sucrose in PBS overnight at $4^{\circ} \mathrm{C}$. One-hundred micrometer coronal brain sections were acquired using a HM430 frozen microtome (Thermo Fisher). Imaging was performed with an Olympus BX51 epifluorescent microscope equipped with QImaging Retiga EXi digital camera or a Leica Wide-field DM5500. The distances of nuclei were calculated using ImageJ.

Immunohistochemistry. Adult male and female mice were euthanized and perfused intracardially with PBS and 4\% PFA. Eyes were removed from the skull and placed in 4\% PFA for $10 \mathrm{~min}$ at room temperature (RT). For whole-mount preparations, retinas were dissected out of the eyes and placed in 4\% PFA for $1 \mathrm{~h}$. For cryosectioning, the lens and vitreous were removed and the whole eye was equilibrated in $30 \%$ sucrose overnight at $4^{\circ} \mathrm{C}$. Whole eyes were then inserted into Tissue-Tek OCT Compound (Sakura Finetek), frozen using dry ice. Twenty micrometer sections were obtained from a CM1520 Cryostat (LeicaMicrosystems) and collected on glass Plus slides (Fisher Scientific). Sections were dried for $12 \mathrm{~h}$ at room temperature. For immunohistochemistry, the sections were rehydrated in PBS for $5 \mathrm{~min}$. Retinas and retinal sections were then placed in blocking solution ( $5 \%$ goat serum, $0.25 \%$ Triton $\mathrm{X}-100$ in PBS) for $1 \mathrm{~h}$ at RT. The following antibodies were diluted 1:1000 in blocking solution and retinas were placed in solution at $4^{\circ} \mathrm{C}$ overnight: Tbr2 chicken polyclonal (Lifespan), Brn3a goat polyclonal (Santa Cruz Biotechnology), or ChAT rabbit polyclonal (Millipore). Slides were washed in PBS with $1 \%$ Triton X-100 (PBST) for $10 \mathrm{~min} 3 \times$ and then incubated with the appropriate fluorescently-conjugated secondary antibody (AlexaFluor 488 or AlexaFluor 555, Thermo Fisher) diluted 1:1000 for $1 \mathrm{~h}$ at RT. Slides were washed with PBST $10 \mathrm{~min} 3 \times$ and a glass coverslip was mounted with Fluoromount (Southern Biotech). Imaging was performed with an Olympus BX51 epifluorescent microscope equipped with QImaging Retiga EXi digital camera.

Histochemistry. Adult (P40-P60) mice of each sex were euthanized and perfused intracardially with PBS and $4 \%$ PFA. Brains were removed, placed in $4 \%$ PFA overnight at $4^{\circ} \mathrm{C}$, then soaked in a $30 \%$ sucrose solution in PBS overnight at $4^{\circ} \mathrm{C}$. Whole brains were then inserted into Tissue-Tek OCT Compound (Sakura Finetek), placed on dry-ice for 30 $\mathrm{min}$, and $20 \mu \mathrm{m}$ sections were obtained from a CM1520 Cryostat (LeicaMicrosystems) at $-22^{\circ} \mathrm{C}$ and collected on glass Plus slides (Fisher Scientific). Sections were allowed to dry for $12 \mathrm{~h}$ at RT. For $4^{\prime}, 6-$ diamidino-2-phenylindole (DAPI) staining, the sections were rehydrated in PBS for $5 \mathrm{~min}$ and placed in a $1 \mu \mathrm{g} / \mathrm{ml}$ solution of DAPI in PBS for $5 \mathrm{~min}$ before coverslipping. Those stained for NISSL were dehydrated, incubated in $100 \%$ xylene and rehydrated by descending ETOH then stained with $2 \%$ cresyl violet as described previously (Kádár et al., 2009). For cytochrome oxidase staining adult brains were flattened between glass slides in $4 \%$ PFA overnight then placed in 30\% sucrose overnight at $4^{\circ} \mathrm{C}$. One-hundred micrometer coronal brain sections were acquired using a HM430 frozen microtome (Thermo Fisher). Sections were placed in a solution of $5 \%$ sucrose, $0.03 \%$ cytochrome C, $0.02 \%$ catalase, $0.05 \%$ DAB in phosphate buffer $\left(0.5 \mathrm{M} \mathrm{NaH}_{2} \mathrm{PO}_{4}, 0.15 \mathrm{M}\right.$ $\mathrm{Na}_{2} \mathrm{HPO}_{4}, \mathrm{pH} 7.4$ ) overnight at $37^{\circ} \mathrm{C}$, quenched with $0.1 \% \mathrm{NaN}_{3}$, and 
coverslipped (Triplett et al., 2012). All imaging was performed with an Olympus BX51 epifluorescent microscope equipped with QImaging Retiga EXi digital camera or Keyence BZ-9000.

In situ RNA hybridization. In situ probes for ephrin-A5 (nucleotides 102-682 of the open reading frame) and EphA7 (nucleotides 721-1193) were used to make antisense and sense digoxigenin labeled RNA probes. P2 whole-brain $20 \mu \mathrm{m}$ coronal sections were acquired using a CM1520 Cryostat (LeicaMicrosystems) and in situ hybridization was done as previously described (Feldheim et al., 1998). Stained sections were photographed using a Keyence BZ-9000.

Silicon probe in vivo electrophysiology. Visual response properties of collicular neurons were obtained using 64 ( 2 control, 3 Tra $2 \beta \mathrm{cKO}$ ) or 128 ( 1 control) channel silicon probes (Du et al., 2011), while the mouse was awake-behaving on a spherical treadmill (Niell and Stryker, 2010).

On the day of recording, the mouse was anesthetized with isoflurane (3\% induction, $1.5-2 \%$ maintenance), and a craniotomy ( $\sim 1.5 \mathrm{~mm}$ diameter) was performed at a site that was $0.6 \mathrm{~mm}$ lateral from the midline (left hemisphere) and $3.7 \mathrm{~mm}$ posterior from the bregma. The probe was inserted through the cortex to the SC (in control mice); the bottom electrode was located $1300-1800 \mu \mathrm{m}$ from the cortical surface. Activity in the $\mathrm{SC}$ was identified by displaying either an ON or OFF flashing spot on a computer monitor and determining whether visual responses were localized to a restricted location of the visual field. The visual stimulus monitor was placed $25 \mathrm{~cm}$ away from the right side of the mouse and recordings were done $30 \mathrm{~min}$ after probe insertion. During the recording session, the mouse was allowed to behave freely on the treadmill.

Two different visual stimuli were used to evaluate visual responses of the SC neurons: (1) $10^{\circ}$ diameter flashing circular spots on a $10 \times 7$ grid with $10^{\circ}$ spacing: the $500 \mathrm{~ms}$ flashes were either ON (white) or OFF (black) on a gray background and a $500 \mathrm{~ms}$ gray screen was inserted after each stimulus presentation. Stimulus contrast and location on the grid were chosen in a random order, and each pattern was repeated 12 times (Wang et al., 2010). (2) Drifting sinusoidal gratings: the parameters were the same as those used by Niell and Stryker (2008). Briefly, sinusoidal gratings moving in 12 directions with $0.01-0.32$ cycles $/{ }^{\circ}(\mathrm{cpd})$ spatial frequencies with a logarithmic scale with a factor of 2 as an interval. Temporal frequency and duration were $2 \mathrm{~Hz}$ and $1.5 \mathrm{~s}$, respectively. In addition to these stimuli, an alternating checkerboard stimulus $(4 \mathrm{cpd}$ square wave, alternating at $0.5 \mathrm{~Hz}$ ) was used to determine the current sink in superficial SC (Zhao et al., 2014). All visual stimuli were synchronized with digital pulses sent from the stimulus computer to the data acquisition system.

For spike-sorting and local field potential analysis, we used customdesigned software as described previously (Litke et al., 2004). Briefly, a level 5 discrete wavelet filter (cutoff frequency $\sim 313 \mathrm{~Hz}$; Wiltschko et al., 2008) was applied to the recorded data. The high-pass part was used for spike-sorting to find single units and filtered data were also subjected to motion artifact removal; the low-pass part was used for a current source density analysis. The average motion artifact shape was estimated by averaging signals from all the recording channels. The estimated artifact was then subtracted from each channel with a multiplication factor that reduces the noise level of the channel most effectively (determined by the least-squares method). In the following steps, in addition to what was described by Litke et al. (2004), we used Bayesian information criterion to optimize the numbers of clusters in the expectation maximization step (Fraley and Raftery, 1998) and also introduced isolation distance $(>20)$ and L-ratio $(<0.1)$ as criteria of a good cluster (Schmitzer-Torbert et al., 2005).

Current source density (CSD) for each shank was calculated as described previously (Niell and Stryker, 2008) using the middle column of electrodes, whereas the center of gravity (CoG) of the current sink (negative part of CSD) was used to estimate the center of visual response in the SC [see also supplemental information from Zhao et al. (2014)]. To restrict analysis to superficial SC neurons, we only used neurons that have a depth $\pm 250 \mu \mathrm{m}$ from the CoG of the current sink in our analysis.

Significance of the response was evaluated at each grid location of the flashing spot stimulus. First, the poststimulus time histogram was calculated using a $50 \mathrm{~ms}$ bin size. If the firing rate of a bin exceeds the threshold value, $\bar{F}+5 * \sigma$, where $\bar{F}$ is a mean firing rate of the neuron during entire flashing spot stimulus, and $\sigma$ is a SD of the firing rate based on Poisson statistics, the response is considered significant. If a cell had significant responses to the white or black flashing spot only, the cell was considered to be an ON or OFF cell, respectively; if it had significant responses to both white and black spots, it was considered to be an ON-OFF cell. Receptive field diameters were estimated by the number of significant grid locations; each location accounted for an area of 100 square degrees. The diameter was approximated using a circle that has the same area as the actual receptive field area. Namely, $d=2 \sqrt{A / \pi}$, where $d$ and $A$ are the diameter and the area of the receptive field, respectively.

Direction and orientation selectivity were analyzed with the same methods found in (Niell and Stryker, 2008). Briefly, direction selective index (DSI) is a difference over sum (DoS) of responses to the preferred direction and its opposite direction; Orientation Selective Index (OSI) is a DoS of responses to the preferred orientation and its orthogonal orientation. DSI $\geq 0.5$ was used as a criterion of direction selective cells; OSI $\geq 0.5$ and DSI $<0.5$ were used as criteria of orientation selective cells.

Fear conditioning. The ability to sense light stimuli was assessed using an automated fear conditioning system for mice (Coulbourn Instruments) with the following parameters: Day 1, acquisition: 3 min habituation in Chamber A, followed by 10 light shock pairings with an average inter trial interval of $120 \mathrm{~s}$ consisting of $8 \mathrm{~s}$ of flashing light, $0.5 \mathrm{~s}$ on $0.5 \mathrm{~s}$ off, followed by $2 \mathrm{~s}$ of flashing light paired with $0.3 \mathrm{~mA}$ foot shock. Day 2, retention: $3 \mathrm{~min}$ habituation in Chamber B, followed by $3 \mathrm{~min}$ of continual flashing light. Freezing during cued retention was recorded by an automated system (Graphic State3.0 software, Coulbourn Instruments). Before statistical analysis, all freezing intervals $>2 \mathrm{~s}$ in length during acquisition of cued retention were summed in $60 \mathrm{~s}$ intervals.

Cued swim maze. The water maze consisted of a round white tank $4 \mathrm{ft}$ in diameter and $2 \mathrm{ft}$ tall filled with $\sim 10 \mathrm{in}$. of water. All external visual cues were removed. The water temperature was maintained at $\sim 22^{\circ} \mathrm{C}$ during all trials. Animals were tracked using AnyMaze (Stoelting) video tracking system. On Day 1, four trials were conducted. The mouse was placed in the pool at one of four defined compass points around the edge of the pool and a clear platform was placed in one of four defined quadrants. Mouse placement in the pool and platform location varied across each trial. The mouse was given $60 \mathrm{~s}$ to find the platform, which was marked with a blue visual cue. Upon reaching the platform, the mouse was left on the platform for $5 \mathrm{~s}$ before being returned to its home cage. If the mouse was unable to find the platform, it was placed on the platform for $5 \mathrm{~s}$. On Day 2, the preceding procedure was replicated, but this time the cue was a flashing white light. On Day 3 , the preceding procedure was replicated for the first two trials. During the last two trials, the cue was removed. The amount of time needed to find the platform was used to assess the mouse's perceptive ability. Tra $2 \beta$ cKO animals can display a severe circling phenotype that can limit their ability to orient during the water maze task. The average number of circles per control animal across all three trials was $23.8 \pm 11.7 \mathrm{SD}$, any animal that circled $>150$ times across all three trials was removed from the data analysis $(n=3)$.

Pupillary light response. To measure the pupillary light response, both male and female mice were dark adapted for 1 min under infrared light. While under infrared light, mice were filmed using a Sony Handycam DCR-HC96 for $10 \mathrm{~s}$ to obtain a baseline reading. This was followed by exposure of the contralateral eye to $460 \mathrm{~nm}$ LED light for $30 \mathrm{~s}$ at the high-light condition $\left(2.9 \mathrm{~mW} / \mathrm{cm}^{2}\right)$. Then, following several minutes in dark conditions, the animals were exposed to low-light condition (172 $\mathrm{mW} / \mathrm{cm}^{2}$ ). Light levels were controlled using neutral density filters. Movies were converted into still photos using MPEG Streamclip and the percentage of pupil constriction was calculated using ImageJ. The percentage pupil constriction was calculated as the difference in pupil size between dark-adapted and light-exposed eyes.

Locomotor activity. Activity was measured in $12 \mathrm{~h}$ dark/light cycles for $60 \mathrm{~h}$. The activity chamber consisted of a clear acrylic cage $(43 \times 22 \mathrm{~cm})$ containing a $3 \times 8$ array of photo beams mounted $2.5 \mathrm{~cm}$ from the chamber floor. The photobeam breaks were recorded using PAS software (San Diego Instruments). Each mouse was placed individually into a cage and the number of photo beam breaks was monitored for $60 \mathrm{~h}$ starting at 

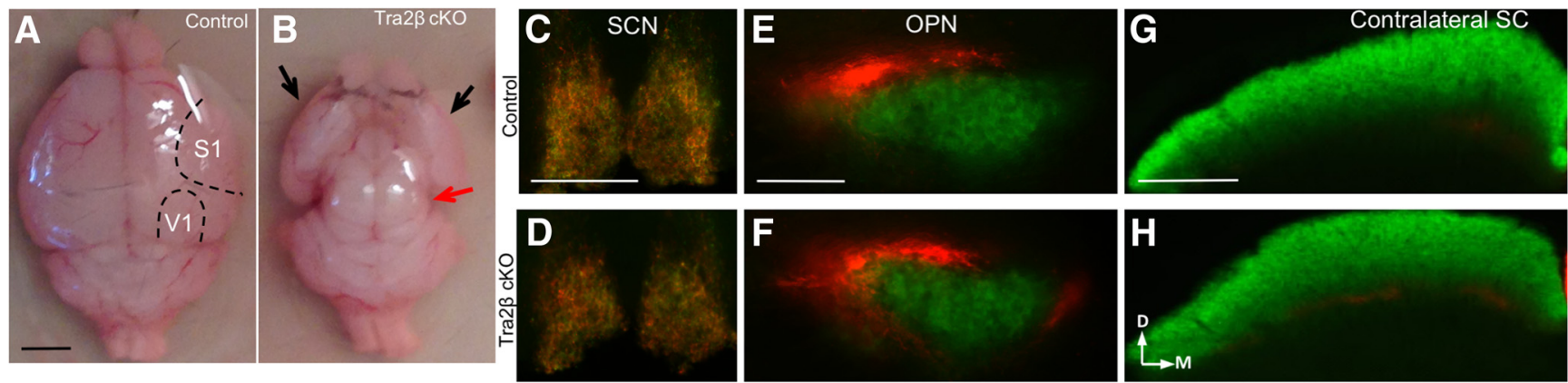
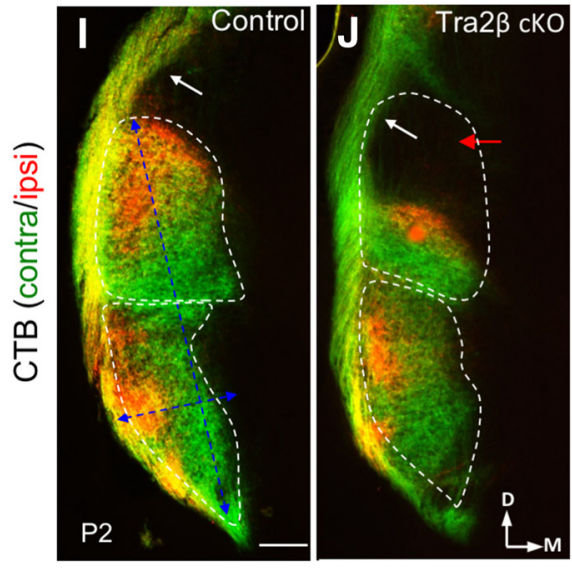

$\mathbf{O}$

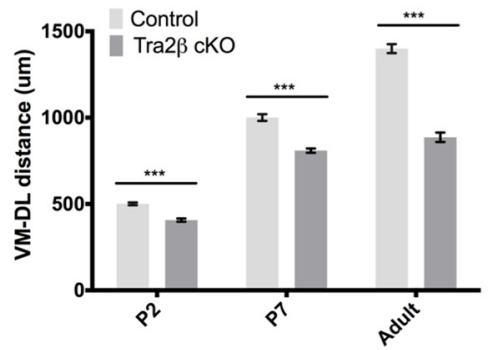

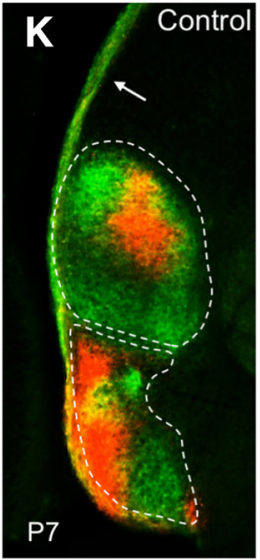

$\mathbf{P}$

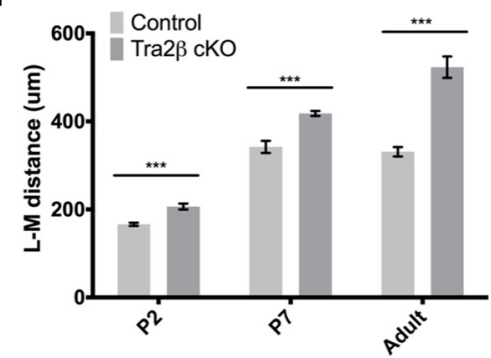

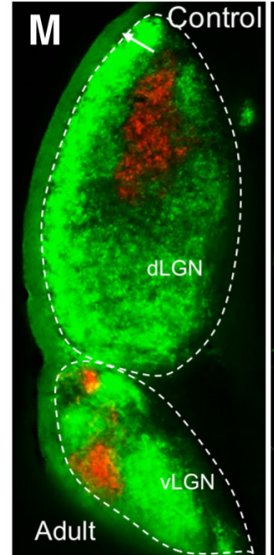

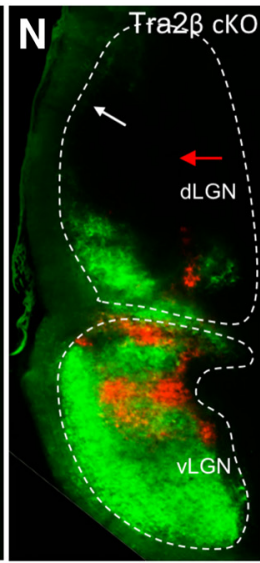

Q

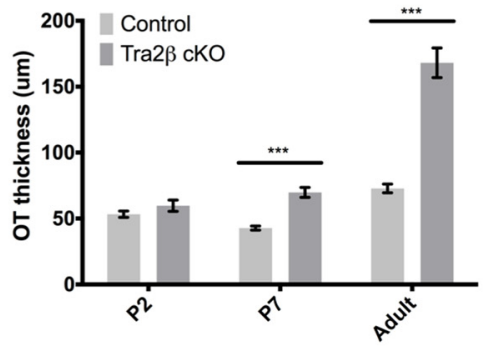

Figure 1. Emx1-Cre; Tra2 $\beta$ mutant mice have severe cortical tissue loss and loss of RGC inputs to the dLGN. Dorsal view of control (A) and Tra2 $\beta^{\text {floxfllox; }}$ Emx1-Cre (Tra2 $\beta$ cK0) mice ( $\left.\boldsymbol{B}\right)$ adult brains. Mutants show complete loss of dorsal and medial cortex. Red arrow points to completely exposed superior and inferior colliculi. Black arrows indicate the ventral-lateral portion of cortex that remains in the mutant. $\boldsymbol{C}-\boldsymbol{H}, \mathrm{RGC}$ projections to subcortical visual nuclei were labeled by injection of CT $\beta$-488 (green) into the left eye, and CT $\beta$ - 555 (red) into the right eye of adult (P45-P80) control and Tra $2 \beta$ CKO animals. RGC axons in both control and Tra2 $\beta$ CKO mice project to nonthalamic retinorecipient nuclei: SCN $(\boldsymbol{C}, \boldsymbol{D})$, OPN and $(\boldsymbol{E}, \boldsymbol{F})$, and SC $(\boldsymbol{G}, \boldsymbol{H})$. I-N, Left hemisphere of retinogeniculate projections in control and $\operatorname{Tra} 2 \beta$ cK0 at three different ages: $\mathrm{P2}(\boldsymbol{I}, \boldsymbol{J}), \mathrm{P} 7(\boldsymbol{K}, \boldsymbol{L})$, and adult $(\boldsymbol{M}, \boldsymbol{N})$. Tra2 $\beta$ cKO dLGN lacks contralateral (green) and ipsilateral (red) innervation (red arrows) that is evident by $P 2$. White dashed line indicates total area of both vLGN and dLGN. Tra $2 \beta$ cKO mice also have an increased thickness of optic tract (white arrows). $\boldsymbol{P}$, Dorsolateral to ventromedial length of the dLGN is significantly reduced at all ages; ${ }^{* * *}$ (SEM) $p<0.005, n=3$ Student's $t$ test. $\mathbf{Q}$, Medial to lateral width of the dLGN shows significant increase at all ages (SEM) $p<0.005, n=3$ Student's $t$ test. $\boldsymbol{R}$, Thickness of optic tract is significantly larger at P7 (SEM) $p<0.01$ and adult (SEM) $p<0.005$ Tra2 $\beta$ mutant mouse, $n=3$ Student's $t$ test. Scale bars: $A, \boldsymbol{B}$, $2.5 \mathrm{~mm} ; \boldsymbol{C}, \boldsymbol{D}, 200 \mu \mathrm{m} ; \boldsymbol{E}, \boldsymbol{F}, 500 \mu \mathrm{m} ; \boldsymbol{G}, \boldsymbol{H}, 200 \mu \mathrm{m} ; \boldsymbol{I}-\boldsymbol{N}, 100 \mu \mathrm{m}$.

18:00 h. The total number of photo beam breaks per $1 \mathrm{~h}$ interval was recorded.

\section{Results}

Cortical innervation is necessary for targeting image-forming RGC axons to the dLGN

To determine whether cortical development is required for normal RGC axon targeting, we anterogradely traced the RGC axonal projections in Tra $2 \beta^{\text {flox/flox}}$; Emxl-Cre ${ }^{+}$mice (hereafter referred to as $\operatorname{Tra} 2 \beta$ cKO mice). In these mice $\operatorname{Tra} 2 \beta$ is deleted from most of the developing cortex, and cortical progenitor cells that lack Tra2 $\beta$ apoptose (Roberts et al., 2014). Although viable, this mouse lacks $\sim 85 \%$ of the neocortex, and has a complete loss of the visual cortex (Roberts et al., 2014). A comparison of brains from age matched littermate controls (a combination of $\operatorname{Tra} 2 \beta^{\mathrm{fl} /+}$; Emx1-Cre ${ }^{+}, \operatorname{Tra} 2 \beta^{+/+}$; Emx1-Cre ${ }^{+}, \operatorname{Tra} 2 \beta^{\mathrm{fl} /+}$, or
$\operatorname{Tra} 2 \beta^{\mathrm{fl} / \mathrm{fl}}$ no Cre; Fig. $1 A$ ) and Tra $2 \beta \mathrm{cKO}$ (Fig. $1 B$ ) mice demonstrates the severe loss of cortex in the Tra $2 \beta$ cKO (Roberts et al., 2014). To determine whether the lack of a cortex affects RGC axon targeting, RGC axons from control and Tra $2 \beta \mathrm{cKO}$ mice were labeled via an injection of cholera toxin subunit $\beta$ conjugated to fluorophores (CT $\beta-488$ and CT $\beta$-555) into each eye $2 \mathrm{~d}$ before harvesting the brains. Coronal sectioning of the brain allows the visualization of both contralateral and ipsilateral RGC axons in all of the retinal recipient nuclei (Pfeiffenberger et al., 2005; Triplett et al., 2014). Whereas the SCN, OPN, and SC show no significant differences in RGC axon distributions between the two genotypes (Fig. $1 C-H$ ), there are dramatic changes in the innervation pattern of RGC axons in the visual thalamus, including the vLGN, IGL, and dLGN (Fig. $1 I-N$ ). Most dramatically, the dorsomedial portion of the dLGN lacks RGC axons in the 
Table 1. Summary of thalamic innervation and optic tract thickness measurements

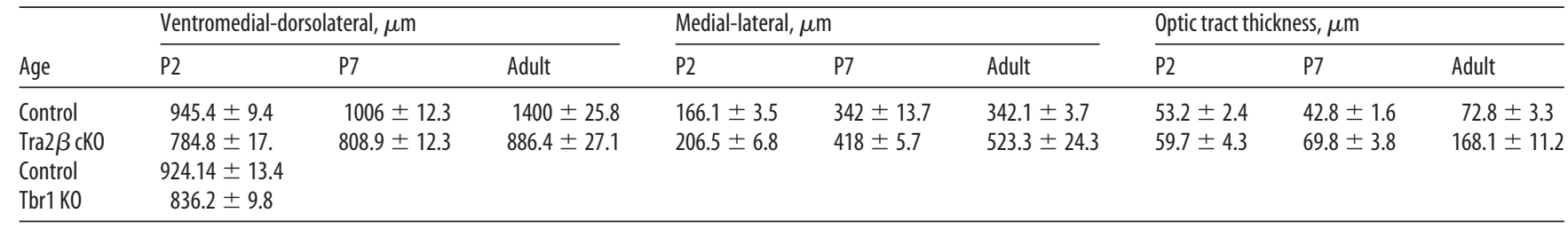
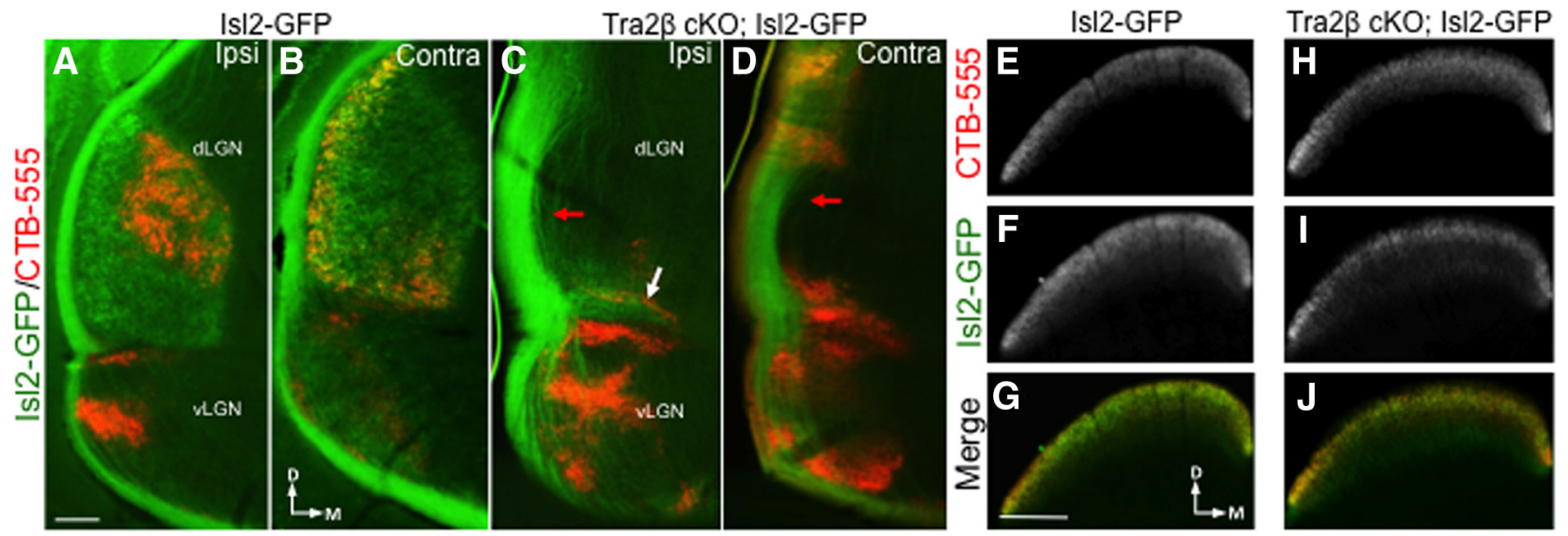

Figure 2. The development of a cortex is essential for image-forming RGC axons to project to the dLGN. $\boldsymbol{A}-\boldsymbol{D}$, One-hundred micrometer coronal sections through the mouse visual thalamus in an adult (P45-P80) IsI2-GFP littermate control mouse ( $\boldsymbol{A}, \boldsymbol{B})$ and Tra2 $\beta$ cK0; Isl2-GFP adult mouse ( $\boldsymbol{C}, \boldsymbol{D})$. Is|2-GFP ${ }^{+}$(green) and (T $\beta$-labeled (red) axons in both ipsilateral ( $\left.\boldsymbol{A}, \boldsymbol{C}\right)$ and contralateral ( $\boldsymbol{B}$, D) projections. IsL2-GFP axons fail to terminate in the Tra2 $\beta$ cKO dLGN except for a minor ventral fragment (white arrow). The optic tract is less fasciculated in the Tra2 $\beta$ cKO LGN (red arrows). $\boldsymbol{E}-\boldsymbol{J}$, Sections through the SC of the same mice. IsI2-GFP control mouse SC sections labeled with CTB-555 (E), IsL2-GFP (F), and merge $(\boldsymbol{G})$ show that innervation of the SC is similar to that of Tra2 $\beta$ cK0; Is|2-GFP SC innervations, (TB-555 (H), Is|2-GFP (I), and merge (J). Scale bars: $\boldsymbol{A}-\boldsymbol{D}, 100 \mu \mathrm{m} ; \boldsymbol{E}-\boldsymbol{J}, 200 \mu \mathrm{m}$.

Tra $2 \beta$ cKO. This void area of the dLGN can be detected as early as $\mathrm{P} 2$, an age before cortical innervation of the dLGN is thought to begin (Seabrook et al., 2013), and loss of innervation continues into adulthood. The ventromedial to dorsolateral extent of the inputs within the entire LGN are reduced significantly in Tra $2 \beta$ cKO even at early time points (Table 1 ; Fig. $1 P$ ). The length of innervation of RGC axons in the vLGN of Tra $2 \beta$ cKO is significantly greater along the medial-lateral axis at each age tested ( $\mathrm{Ta}-$ ble 1; Fig. 1Q). We also find that compared with control, the thickness of the optic tract dorsal to the dLGN is significantly enlarged in Tra $2 \beta$ cKO animals starting at P7 (Table 1; Fig. $1 R$ ). Together, these data show that complete RGC innervation of the dLGN requires a developing cortex.

We wanted to determine whether the RGC axons that do project to the ventral dLGN in the Tra $2 \beta$ cKO are a subset of the imageforming RGCs that normally project there, or whether the nonimage-forming RGCs that normally project to the vLGN or IGL expand into the neighboring dLGN. To distinguish between these hypotheses, we crossed Tra $2 \beta$ cKO mice to an Isl2-GFP reporter line. This line expresses GFP in a subset of RGCs that send axonal projections to the contralateral dLGN and SC, but not any other retinal recipient area (Triplett et al., 2014). We find that Isl2-GFPexpressing axons send few, if any projections to the dLGN of adult Tra $2 \beta$ cKO mice (Fig. $2 A-D$ ), but target the SC normally (Fig. $2 E-J$ ). We also find that Isl2-GFP labeled axons do not aberrantly project to any other retinal recipient areas (data not shown). These results suggest that the axons that target the ventral most portion of the dLGN in Tra $2 \beta$ cKO are likely to be from RGCs that normally target nonimage-forming areas, and that the RGC axons that normally target the dLGN now project solely to the SC.

\section{Morphological and histological features of the Tra2 $\beta \mathrm{cKO}$ retina and thalamus are similar to wild-type}

Because we found that RGC axons no longer project to a large portion of the dLGN, we wanted to assess whether developing without a cortex leads to a change in dLGN or retinal structure. Coronal sections through the thalamus stained with DAPI, NISSL, and cytochrome oxidase all showed that the dLGN can be morphologically identified, is maintained in the thalamus, and is metabolically active (Fig. $3 A-H$ ). We also found that ephrin-A5 and EphA7, genes know to be expressed in gradients in the vLGN and dLGN during development (Feldheim et al., 1998; Rashid et al., 2005), maintain their graded expression patterns in the Tra $2 \beta$ cKO mutants (Fig. $3 I-L)$.

Retinal and RGC development are also unaffected in Tra2 $\beta$ cKO mice. Using the tdTomato Cre reporter line (Ai9) we found very few tdTomato ${ }^{+}$cells $\left(1.3 \pm 0.1 \mathrm{SEM}\right.$ tdTomato $^{+}$vs $34.1 \pm$ 3.4 SEM DAPI ${ }^{+}$) per $100 \mu \mathrm{m}$ of ganglion cell layer analyzed, demonstrating that the Emx1-Cre is not significantly expressed in the retina. We also found no differences in the distribution or number of image-forming and non-image-forming RGCs based on immunocytochemistry of retinas stained with Brn3a, a transcription factor expressed in image-forming RGCs (Quina et al., 2005) and Tbr2, a protein expressed selectively in RGCs that project to non-image-forming areas (Sweeney et al., 2014; Fig.

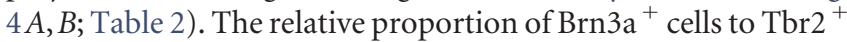
cells was also not significantly different (Table 2 ). General retinal structure and lamination patterns were also normal in the mutant as assayed by DAPI and Choline acetyl transferase (ChAT) staining (Fig. 4C,D). 

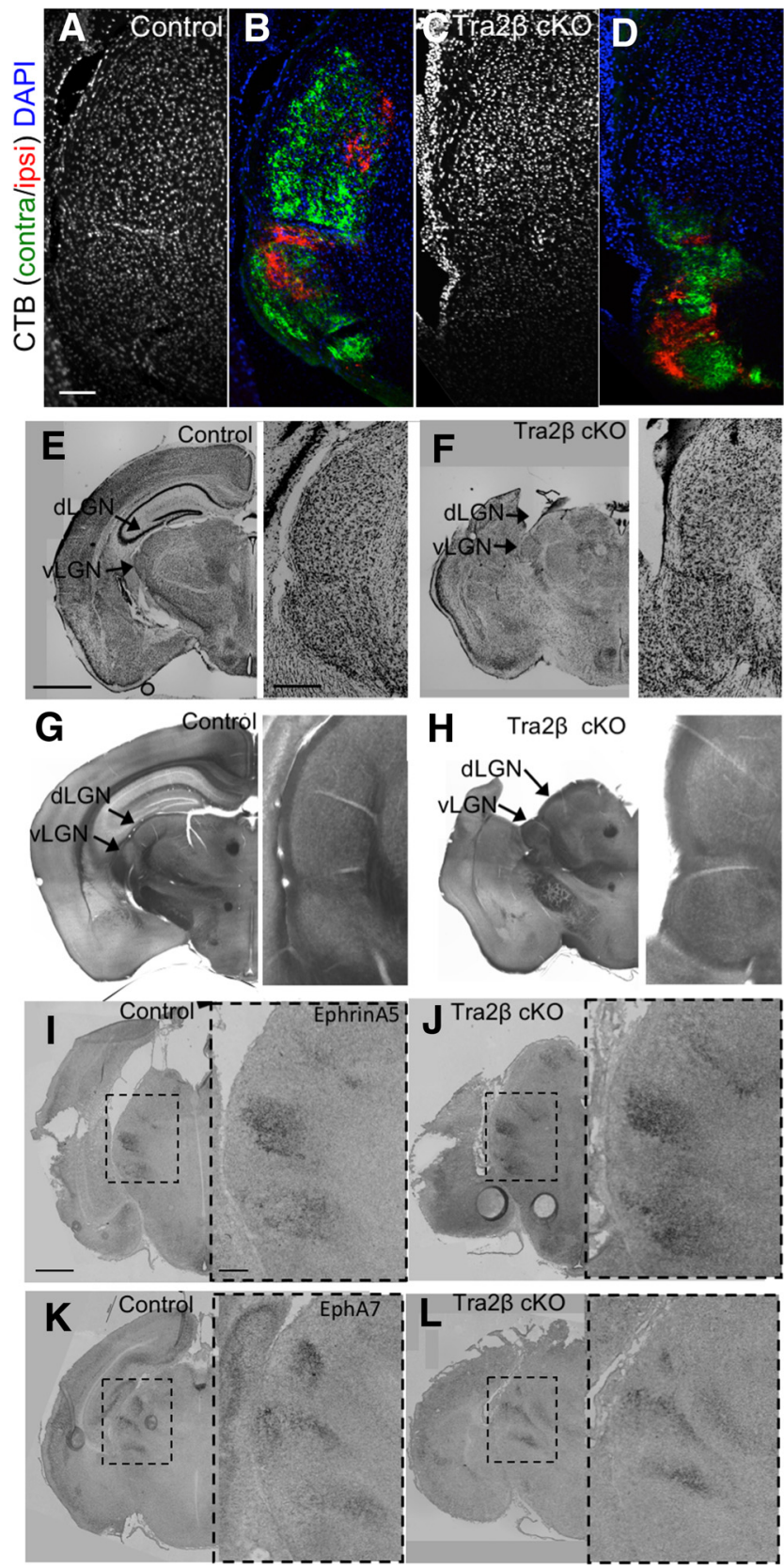

Figure 3. Tra $2 \beta$ cKO LGN tissue is morphologically similar to that of control animals. $\boldsymbol{A}-\boldsymbol{D}$, $20 \mu \mathrm{m}$ coronal sections of adult (P45-P80) animals stained with DAPI (blue) confirm the existence of cell nuclei in controls $(\boldsymbol{A})$ and $\operatorname{Tra} 2 \beta \mathrm{cKO}(\boldsymbol{C})$ visual thalamus, verified by labeling $\mathrm{RGC}$ axons originating from the left eye with CT $\beta$ - 488 (green) and right eye with CT $\beta$ - 555 (red) in control $(\boldsymbol{B})$ and Tra2 $\beta$ CKO (D). $\boldsymbol{E}, \boldsymbol{F}$, NISSL-stained $50 \mu \mathrm{m}$ sections of adult controls $(\boldsymbol{E})$ and $\operatorname{Tra} 2 \beta$ cKO ( $\boldsymbol{F}$; arrows indicate locations of dLGN and vLGN) have similar staining patterns. $\boldsymbol{G}, \boldsymbol{H}$, Cytochrome oxidase staining of $50 \mu \mathrm{m}$ sections of adult controls $(\boldsymbol{G})$ and $\operatorname{Tra} 2 \beta \mathrm{CKO}(\boldsymbol{H})$ arrows indicate the $\mathrm{dLGN}$ and vLGN have similar staining patterns. $I-L$, RNA in situ hybridization of coronal sections from $\mathrm{P} 2$ animals, dashed box indicates visual thalamus; Ephrin- $\mathrm{A} 5$ expression in control animals $(\boldsymbol{I})$ and Tra2 $\beta$ cKO $(\boldsymbol{J})$; EphA7 expression in controls $(\boldsymbol{K})$ and Tra2 $\beta$ cKO $(\boldsymbol{L})$ show similar patterns. Arrows indicate locations of dLGN and vLGN. Inset, Zoom of original images. Scale bars: $\boldsymbol{A}-\boldsymbol{D}, 100 \mu \mathrm{m} ; \boldsymbol{E}-\boldsymbol{H}, 1 \mathrm{~mm}$; inset, $200 \mu \mathrm{m} ; \boldsymbol{I}-\boldsymbol{L}, 500 \mu \mathrm{m}$; inset, $100 \mu \mathrm{m}$.

\section{Layer 6 cortical inputs to the dLGN are required for proper} retinogeniculate targeting

One major difference between the dLGN and the other retinal recipient areas is that the dLGN receives cortical inputs from layer 6 rather than layer 5 of the visual cortex. To determine whether layer 6 inputs are required for retinogeniculate targeting, we traced the retinal projections in Tbr1-null (Tbr1 KO) mice (Bulfone et al., 1998). In these mice layer 6 cortical neurons take on the fate of layer 5 neurons, as assayed by their expression of cortical layer 5 and layer 6 markers, cell morphology, and the fact that their axons fail to project to thalamic nuclei and instead project to the subcerebral targets of layer 5 neurons (Hevner et al., 2001; McKenna et al., 2011). Tbr1 KO mice die at early postnatal ages, but we were able to anterograde label RGC axon projections at birth and analyze their projection patterns at P2. We then measured the ventromedial to dorsolateral length of RGC innervation within the dLGN of Tbr1 KO and WT littermate controls and found a significant decrease in the Tbrl $\mathrm{KO}$ mice (mutant $835.7 \mu \mathrm{m} \pm 8.9$ SEM; $n=3$; control $929.6 \mu \mathrm{m} \pm 12.7$ SEM; $n=$ $3, p<0.005$, Student's $t$ test). We next compared Tra $2 \beta c K O$ and Tbrl mutant LGN innervation distances and found no significant differences between the two controls (Tra2 $\beta$ controls: 945.4 $\mu \mathrm{m} \pm 9.4 \mathrm{SEM}, n=3$; Tbr 1 controls: $929.6 \mu \mathrm{m} \pm 12.7 \mathrm{SEM}, n=$ 3; $p>0.05$, Student's $t$ test) or the Tra2 $\beta$ cKO and Tbr1 KO mutants (Tra $2 \beta$ cKO $784.8 \mu \mathrm{m} \pm 17.9$ SEM; $n=3$; Tbr1 KO $835.7 \mu \mathrm{m} \pm 8.9$ SEM; $n=3 ; p>0.05$, Student's $t$ test; Fig. $5 A, B$; Table 1). These data suggest that innervation of the visual thalamus by axons from cortical layer 6 during development is necessary for image-forming RGCs to properly target and/or terminate within the dLGN.

\section{The visual response properties of SC neurons are similar between control and Tra2 $\beta$ cKO mice}

Although RGCs can still project to the SC in mice that develop without a cortex, many studies have suggested that the cortical inputs to the SC participate in shaping the visual response properties of a collicular neuron (Wang et al., 2010; Wang and Burkhalter, 2013; Zhao et al., 2014). We measured the visual response properties of SC neurons in Tra $2 \beta \mathrm{cKO}$ and littermatecontrol mice in response to patterned stimuli using 2-shank, 64 or 128 channel silicon probes in the SC (Fig. 6A) to record the visual response properties of $\mathrm{SC}$ neurons in awake mice that are head-fixed on a freely floating Styrofoam ball used as a spherical treadmill while viewing a computer monitor (Fig. 6A, $B$; Dombeck et al., 2007; Harvey et al., 2009; Niell and Stryker, 2010). We displayed flashing spots (Wang et al., 2010) and drifting sinusoidal gratings (Niell and Stryker, 2008) to the mice. We found that the visual response properties of $\mathrm{SC}$ neurons to these stimuli were similar in the two sets of mice. Using the stationary spot stimulus we found that both control and Tra $2 \beta \mathrm{cKO}$ contained ON, OFF, and ON-OFF responses with no difference in RF size distributions between control and mutant (Fig. 6B). However, we did find a change in the proportions of these cell types; the mutants having a decrease in the number of ON-OFF cells and an increase in OFF cells compared with controls, although all three populations of cell types are found in each animal (Fig. 6C). Using a drifting sinusoidal grating stimulus we found that both control and mutant have similar proportions of direction selective and orientation selective SC neurons (Fig. $6 D-F$ ).

\section{Tra2 $\beta$ cKO animals have normal non-image-forming visual functions}

Does developing without a cortex have an impact on visuallyevoked behaviors? We tested the Tra $2 \beta \mathrm{cKO}$ mice on a number of visually dependent tasks that are thought to use distinct retinal circuits. Consistent with normal innervation of the OPN and $\mathrm{SCN}, \operatorname{Tr} 2 \beta \mathrm{cKO}$ mutants display normal performance on behaviors that rely on non-image-forming circuits, including the pupillary light reflex and circadian day/night activity cycles 
(Trejo and Cicerone, 1984; Hattar et al., 2002; Morin and Allen, 2006; Chen et al., 2011). To test the pupillary light reflex, mice were adapted to dark conditions and then exposed to $172 \mathrm{~mW} / \mathrm{cm}^{2}(1 \%)$ and $2.9 \mathrm{~mW} / \mathrm{cm}^{2}(5 \%)$ of light in the contralateral eye and the amount of total pupillary constriction was calculated. At 5\% of light, the percentage of pupil constriction was not significantly different between Tra2 $\beta$ cKO and control mice (mutant $79.08 \pm 2.77 \%$ SEM, $n=11$; control $80.64 \pm 1.8 \%$ SEM, $n=10 ; p>$ 0.05 , Student's $t$ test; Fig. $7 A, B, E)$. Similarly, the percentage of pupil constriction was not significantly different between $\operatorname{Tra} 2 \beta \mathrm{cKO}$ and control mice at $1 \%$ of light (mutant $62.61 \pm 3.67 \%$ SEM, $n=$ 12; control $60.54 \pm 3.98 \%$ SEM, $n=11$; $p>0.05$, Student's $t$ test; Fig. $7 C-E$ ). To test whether $\operatorname{Tra} 2 \beta$ cKO animals have normal day/night activity cycles, Tra $2 \beta$ cKO and control mice were individually housed in cages that monitor activity by recording infrared beam breaks. Beam breaks were measured for $60 \mathrm{~h}$, which included 3 alternating $12 \mathrm{~h}$ light/dark cycles. Tra2 $\beta$ cKO animals were significantly more active compared with control animals during both the light (mutant $335 \pm$

$76 \mathrm{SEM}, n=12$; wild-type $223 \pm 30 \mathrm{SEM}, n=12 ; p<0.05$, Student's $t$ test) and dark cycles (mutant $1254 \pm 160$ SEM, $n=$ 12 ; wild-type $721 \pm 68$ SEM, $n=12$; $p<0.005$, Student's $t$ test; Fig. $7 H$ ). Circadian rhythms in mice, which manifest as increased activity at night compared with the day, were apparent in both Tra $2 \beta$ cKO $(p<0.005$, Student's $t$ test $)$ and wild-type controls $(p<0.005$, Student's $t$ test). Together these data indicate that the SCN and OPN are innervated (Fig. $1 D, F$ ) in Tra $2 \beta \mathrm{cKO}$ and that their associated behaviors are preserved.

\section{Tra $2 \beta$ cKO mice can perform complex visual tasks}

We assessed the performance of Tra $2 \beta \mathrm{cKO}$ mice on two complex behavioral tasks (cued Pavlovian fear conditioning and cued Morris water maze) to determine their ability to use visual perception to guide behavior. In the Pavlovian fear-conditioning task, we tested whether Tra $2 \beta \mathrm{cKO}$ mice could learn to associate a cue (flashing light) with an aversive stimulus (foot shocks). Increased freezing is indicative of a mouse's adaptive response to fear. Freezing upon presentation of the flashing light $24 \mathrm{~h}$ after conditioning indicates functional vision and recognition of the cue. Male and female Tra $2 \beta$ cKO and control mice were conditioned using 10 light/shock pairings (see Materials and Methods). The conditioned mice were placed into a novel context $24 \mathrm{~h}$ after training; time spent motionless was measured both before and during presentation of the cue (flashing light; Fig. 8A). Control mice exhibited a significant increase in time spent freezing after the onset of the flashing light (before: $6.42 \pm 2.53 \mathrm{~s}$ vs after: $24.8 \pm 5.42$ SEM, $n=8 ; p<0.001$, Student's $t$ test). Tra $2 \beta$ cKO also showed a significant increase in time spent freezing after the onset of the flashing light (before: $5.98 \pm 2.69$ s, vs after: $14 \pm 3.39$ SEM, $n=12 ; p<0.005$, Student's $t$ test). A non-conditioned control group was only exposed to the flashing light during Day 1 acquisition and then again $24 \mathrm{~h}$ later. Non-conditioned mice
Table 2. Summary of RGC marker expression using Tbr2 and Brn3A antibodies

\begin{tabular}{llll}
\hline & Brn3A $^{+}$cells $/ \mathrm{mm}^{2}$ & $\mathrm{Tbr2}^{+}$cells $/ \mathrm{mm}^{2}$ & Brn3A $^{+} / \mathrm{Tbr}{ }^{+}$ratio \\
\hline Control & $13200 \pm 1452$ & $4297 \pm 540$ & $3.12 / 1$ \\
Tra2 $\beta$ cK0 & $15209 \pm 574$ & $5292 \pm 309$ & $2.91 / 1$ \\
\hline
\end{tabular}

showed no significant increase in time spent freezing after the onset of the flashing light (before: $5.07 \pm 1.79$ s, vs after: $2.09 \pm$ 0.74 SEM, $n=8 ; p>0.25$, Student's $t$ test) suggesting that the significant increase in freezing apparent in both control and $\operatorname{Tra} 2 \beta \mathrm{cKO}$ mice is due to the visual perception of the flashing light and resulting memory of the aversive stimulus (Fig. $8 B$ ). These data suggest that even in the absence of cortical development, Tra $2 \beta$ cKO mice can perceive a visual stimulus and correlate it to an aversive stimulus.

In the cued Morris water maze task, we assessed whether Tra $2 \beta$ cKO mice could use visual perception of a cue to guide their movement to an escape platform (Prusky and Douglas, 2004; Fig. $8 C$ ). Time to locate an escape platform marked by a visual cue was measured in Tra $2 \beta$ cKO and control mice across 3 consecutive days (Fig. 8D). Decreased time to reach the platform across three training days suggests that control mice learned to use the visual cue to locate the escape platform $(p<0.001, n=$ 13 , ANOVA). Time to reach the platform also significantly decreased in Tra $2 \beta$ cKO mice across the $3 \mathrm{~d}$, suggesting that Tra $2 \beta$ cKO also learned to use the visual cue to locate the platform $(p<$ 0.03, $n=11$, ANOVA; Fig. $8 E$ ). Although Tra $2 \beta \mathrm{cKO}$ mice were able locate the escape platform using visual cues, time to locate the platform was significantly shorter in control mice compared with Tra $2 \beta$ cKO mice ( $p<0.001$, ANOVA). Swim speed was not significantly different between control and Tra $2 \beta$ cKO mice (control: $1.01 \pm 0.05 \mathrm{~m} / \mathrm{s}$; $\mathrm{cKO}: 0.99 \pm 0.05 \mathrm{~m} / \mathrm{s} ; p=0.22$, 


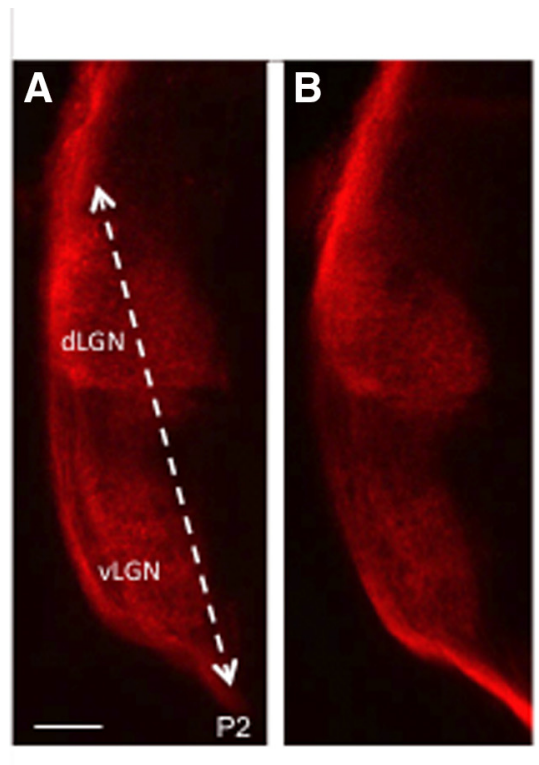

\section{Control}
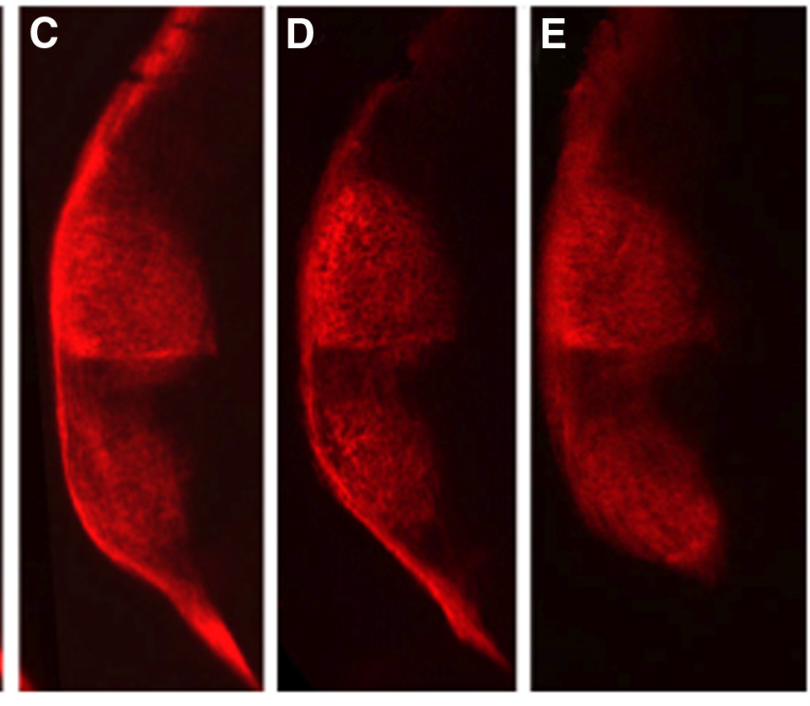

Tbr1\%
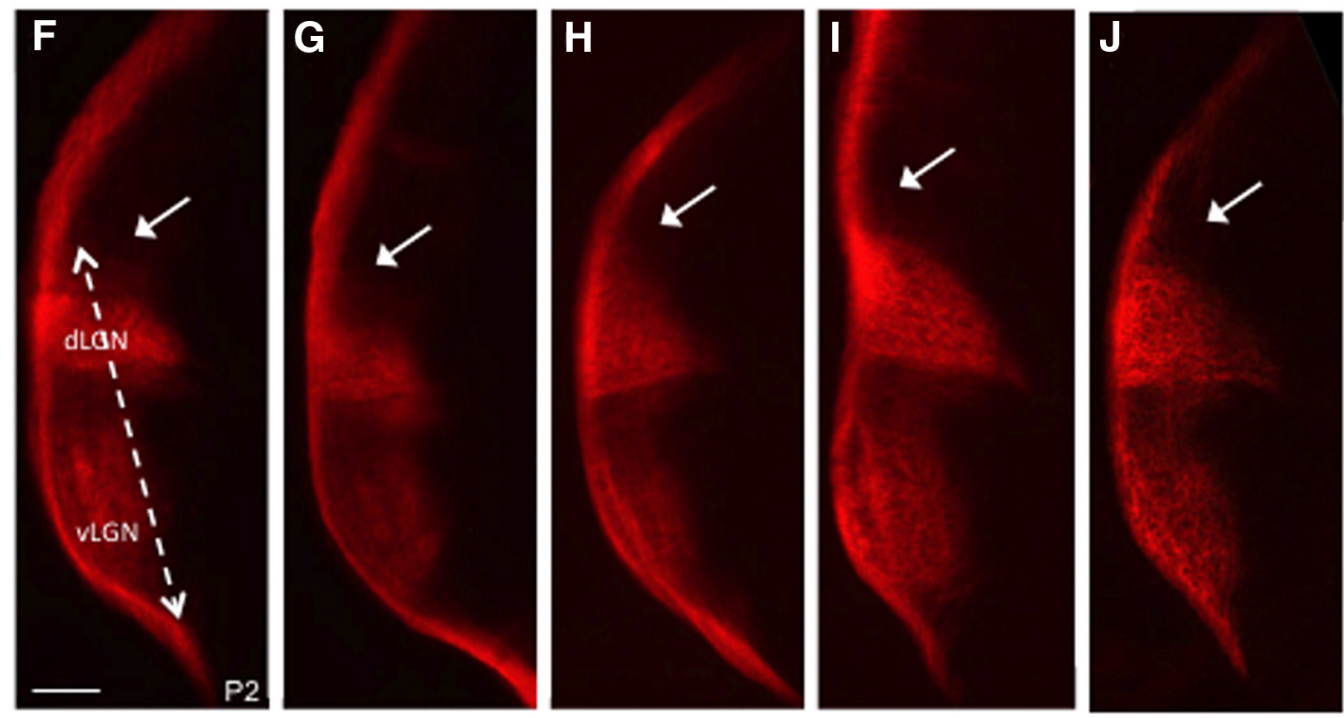

Figure 5. Image forming RGCs fail to properly target the dLGN of Tbr1 K0 animals. $\boldsymbol{A}-\boldsymbol{J}$, Coronal sections of the five P2 control mice $(\boldsymbol{A}-\boldsymbol{E})$ and five Tbr1 K0 mice $(\boldsymbol{F}-\boldsymbol{J})$, that have had their contralateral RGC axons labeled with CT $\beta$-555 (red). Distance of RGC innervation within LGN in control is significantly longer than mutant (dashed line), leaving the dorsal most dLGN lacking innervation (white arrows). Scale bar, $100 \mu \mathrm{m}$.

ANOVA), indicating that impaired performance on the task is not associated with an inability to swim.

During the spatial version of the Morris water maze task in which the platform is hidden, mice develop search strategies to locate the hidden platform (Vorhees and Williams, 2006). To rule out the possibility that Tra $2 \beta$ cKO mice were using strategies in addition to vision to locate the platform, the cue was removed from the platform on the last two trials on Day 3, and we compared the time to reach the platform with and without the cue. Both control and Tra $2 \beta$ cKO mice took significantly longer to find the escape platform after the cue was removed (control: $12.37 \pm 1.86$ vs $36.21 \pm 4.17 \mathrm{~s} ; p<0.001$, ANOVA; cKO: $22.68 \pm$ 2.83 vs $46.91 \pm 3.79 ; p<0.001$, ANOVA) indicating that both control and Tra $2 \beta \mathrm{cKO}$ mice are significantly better when the cue is in place. These data suggest that perception of a visual cue is responsible for the ability of both control and $\mathrm{Tra} 2 \beta \mathrm{cKO}$ mice to locate the hidden platform. This test coupled with the fearconditioning paradigm demonstrates that though they lack a vi- sual cortex and the proper RGC innervation within the dLGN, the Tra $2 \beta$ cKO mice have the ability to perceive light and perform complex visual tasks.

\section{Discussion}

The visual cortex receives visual information from the dLGN and feeds back to many subcortical thalamic and brainstem retinorecipient areas to modulate visual responses and behaviors. Here we describe a novel function of the cortex during development, it is required for the ability of image-forming RGC axons to properly target to the dLGN. The dLGN is unique among RGC targets; it is the only retinorecipient area that sends projections directly to the cortex and is the only area that receives descending projections from layer 6 cortical neurons. This suggests that the axons from these layer 6 neurons may be required for dLGN targeting. Consistent with this, a Tbr1 mutant mouse that has fewer layer 6 inputs to the dLGN also lacks the normal amount of retinal axons in the dLGN. Using physiological recording methods, we find 

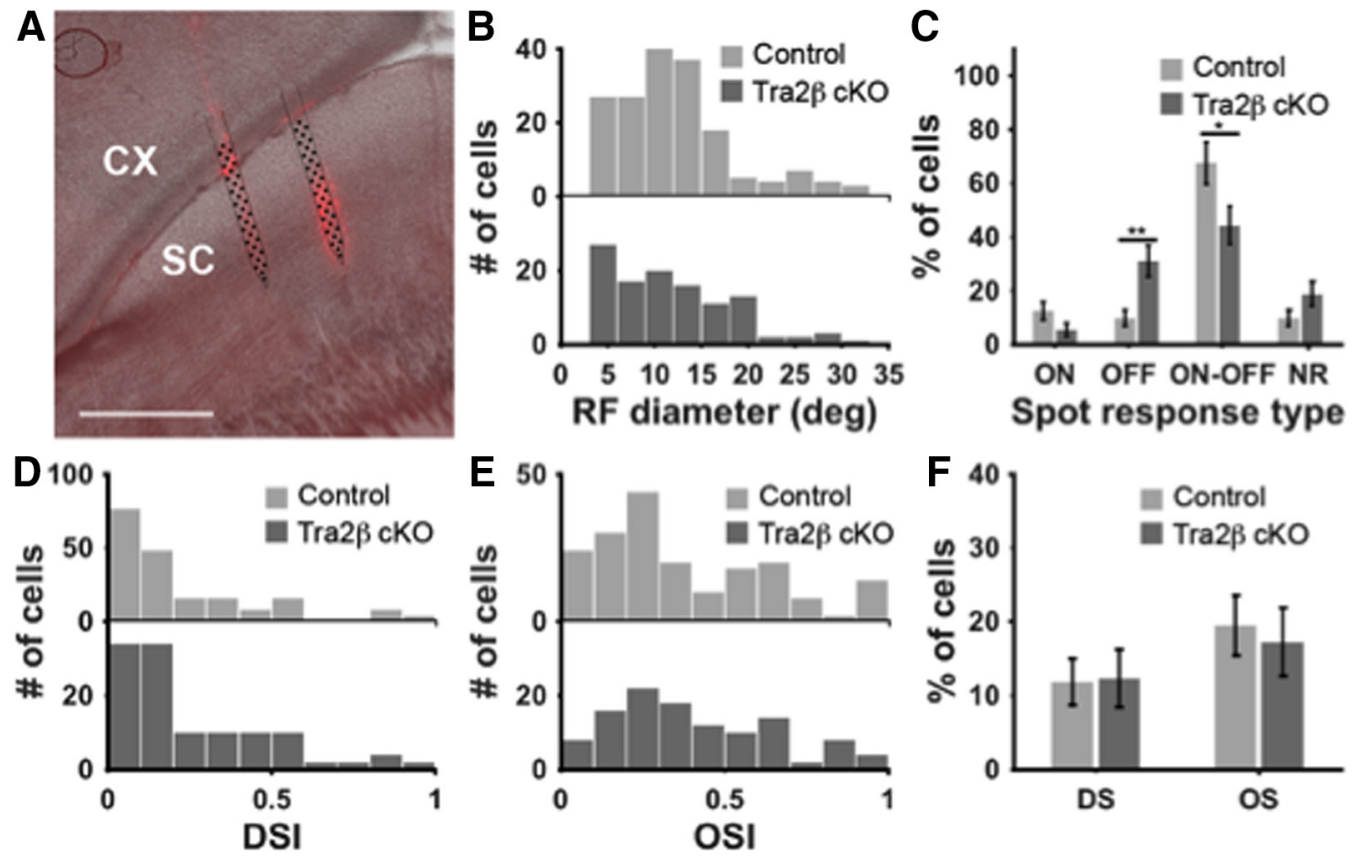

Figure 6. Visual response properties of SC neurons in control and Tra2 $\beta$ cKO mice. $A$, Parasagittal section through the SC in a control mouse (right, anterior; left, posterior) showing Dil traces indicating the location of the inserted probe (red), schematic of the 64-channel probe is shown in black. $\boldsymbol{B}$, Histograms indicating receptive field (RF) diameters of cells as measured in flashing spot responses. There were no significant differences between controls and Tra $2 \beta c K 0$ RF size distributions [Kolmogorov-Smirnov (KS) test, $p>0.05]$. C, Percentage of the $0 \mathrm{~N}, 0 \mathrm{FF}, 0 \mathrm{~N}-0 \mathrm{FF}$, and nonresponsive (NR) neurons in response to the flashing spot stimulus. Error bars represent SD.Significantincrease ofOFFcells, andsignificantdecrease ofON-0FFcellswereobservedin Tra2 $\beta$ cKOmice. ${ }^{* *} p<0.01$ and ${ }^{* *} p<0.05$, respectively.D,E,Histograms oftheDSland OSl ofcellsmeasured indrifting sinusoidal grating stimulus. There were no significant differences between control and Tra $2 \beta$ distributions (KS test, $p>0.05)$. $F$, Percentage of the $0 S$ cells and DS cells. There were no significant differences between control and Tra $2 \beta$ cKO $(p>0.05)$.
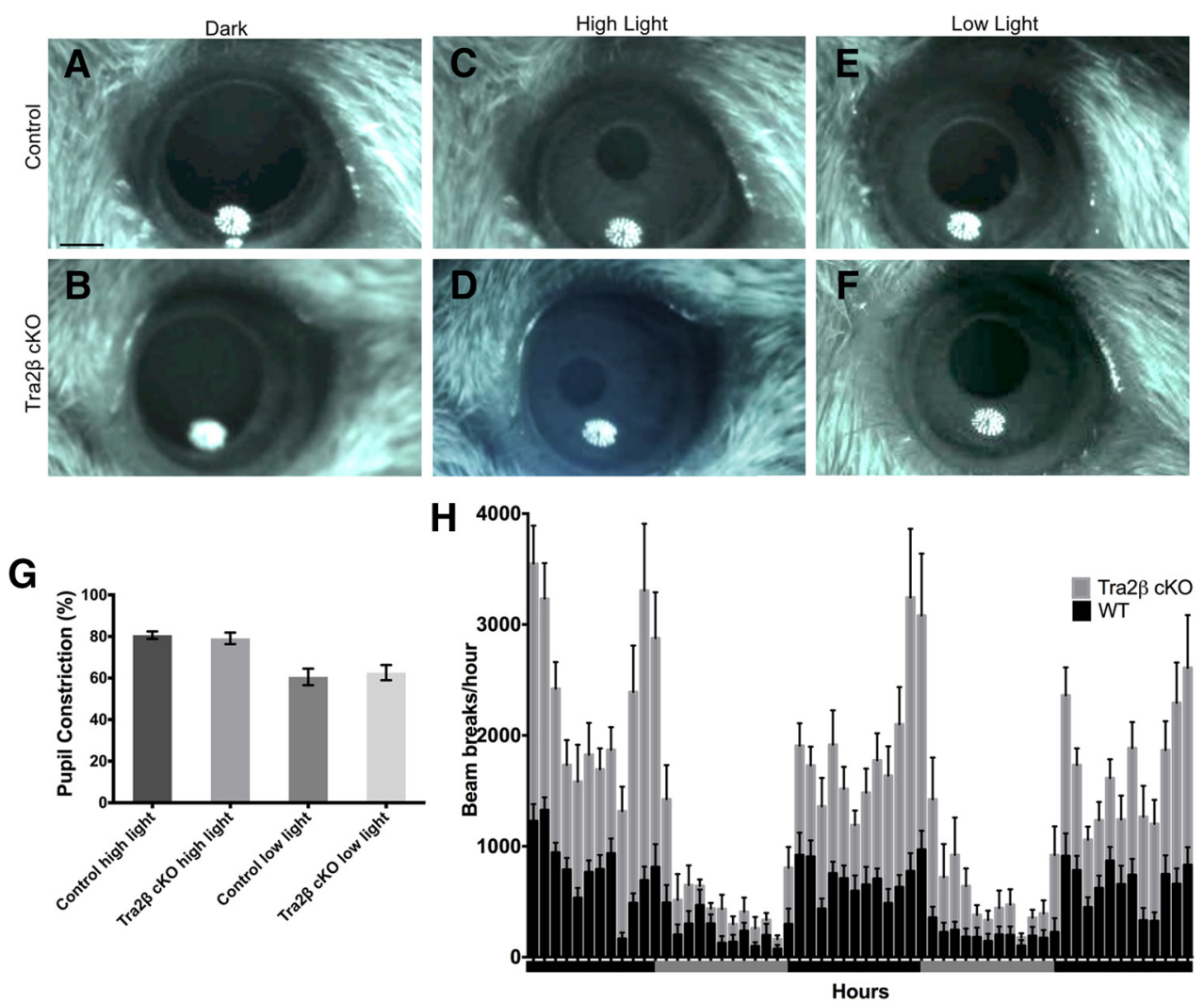

Figure 7. Tra2 $\beta c k 0$ mice have a normal pupillary light reflex and day/night activity cycles. $A-F$, Adult control and $\operatorname{Tra} 2 \beta c K 0$ mice were dark adapted for $1 \mathrm{~min}(\boldsymbol{A}, \boldsymbol{B})$ and then exposed to either high $\left(2.9 \mathrm{~mW} / \mathrm{cm}^{2}\right)(\boldsymbol{C}$, D) orlow $\left(172 \mathrm{~mW} / \mathrm{cm}^{2} ; \boldsymbol{E}, \boldsymbol{F}\right)$ lightintensity presented for 30 s to the contralateral eye, images were captured with an infrared camera. G, Graph showing the percentage pupil constriction in Tra2 $\beta c K 0$ and control mice $(n \geq$ 10), thereis no significant differencein the amount of pupil constriction ateither lightintensity ( $p>0.05$, Student'sttest). $\boldsymbol{H}$, Thenumber of ambulatory beam breaksis shown in $1 \mathrm{~h}$ intervals across $60 \mathrm{~h}$ of alternating $12 \mathrm{~h}$ dark cycles (black bar) and $12 \mathrm{~h} \mathrm{light} \mathrm{cycles} \mathrm{(gray} \mathrm{bar).} \mathrm{Wild-type} \mathrm{animals,} \mathrm{black} \mathrm{columns} \mathrm{and} \mathrm{Tra2} \beta$ cK0 animals, gray columns, error bars (SEM). Scale bar: (in A) A-F, $500 \mu \mathrm{m}$. 

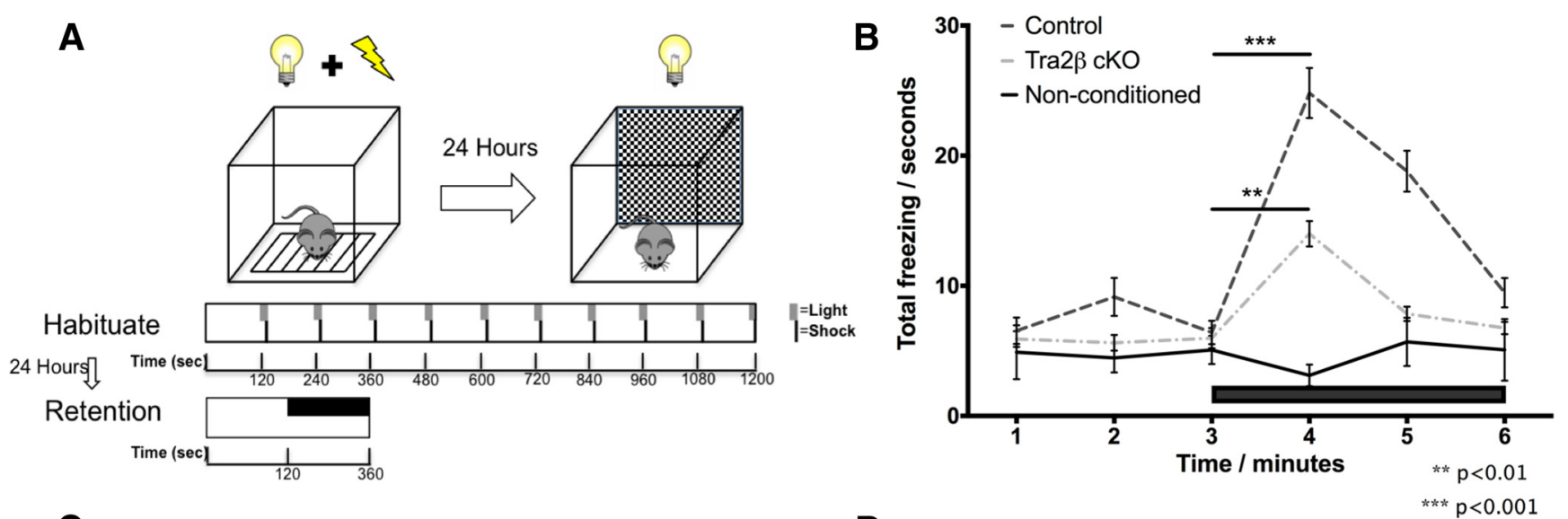

C

D
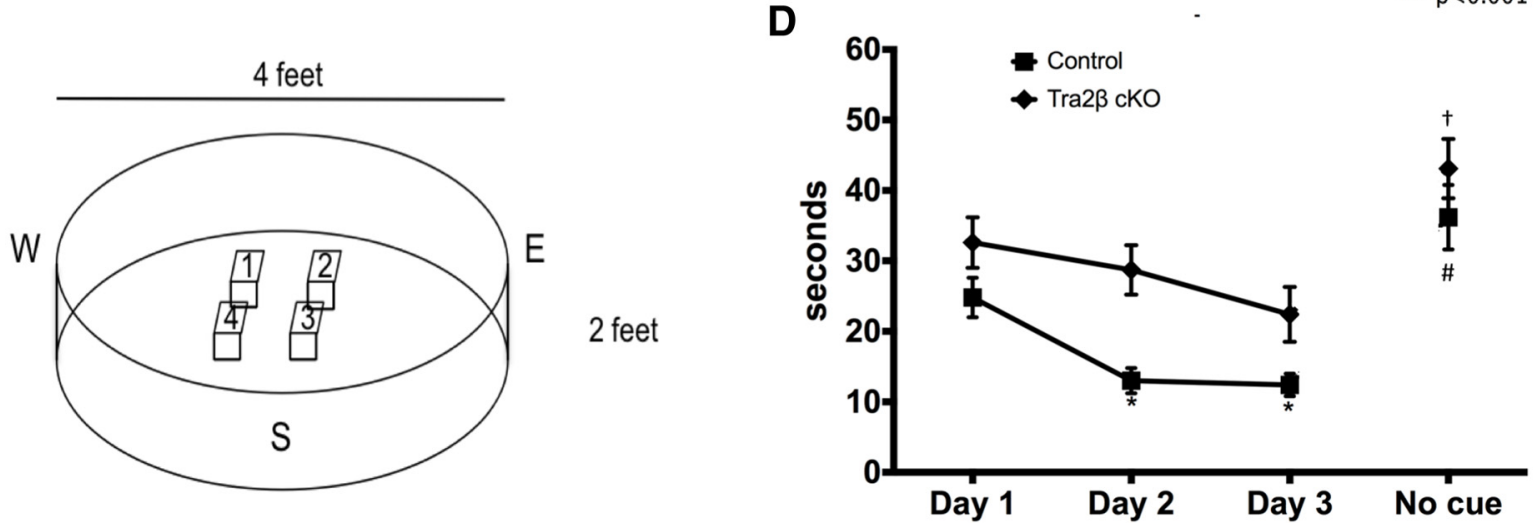

Figure 8. Tra2 $\beta$ animals can be conditioned to associate light with a shock and find a hidden platform using a visual cue. A, Pavlovian fear conditioning design. Animals are conditioned on Day 1 by pairing an unconditioned stimulus (shock) with a conditioned stimulus (flashing light). $0 \mathrm{n}$ Day 2, animals are placed in a novel context, $180 \mathrm{~s}$ of darkness is followed by $180 \mathrm{~s}$ of flashing light (black bar). $\boldsymbol{B}$, There is a significant increase in the amount of freezing behavior in wild-type (black dashed line) and Tra $2 \beta$ cKO (gray dashed line) mice in the $60 \mathrm{~s}$ after the onset of flashing light compared with the previous $60 \mathrm{~s}$ of darkness; control (non-conditioned) animals (black line) do not have a significant response after the onset of light. $\boldsymbol{C}$, Schematic of water maze design indicates four stage positions and three entry points. Days 1 and 2 consist of four trials each day; the platform is labeled with a visual cue. On Day 3, the first two trials the stage is labeled with a visual cue and the next two trials the cue is removed. $\boldsymbol{D}, \operatorname{Tra} 2 \beta \mathrm{cK} 0$ and control animals find the hidden platform significantly better each day and when the cue is removed, the animals find the cue significantly worse. ${ }^{*} p<0.001$ vs control Day $1 ; \# p<0.05$ vs control Day $3 ;{ }^{\dagger} p<0.05$ vs cKO Day 3.

that the loss of cortex does not dramatically affect the receptive field properties of SC neurons. We also find that the development of a cortex is not required for the ability of mice to execute a number of visually dependent behavioral tasks.

\section{Cortical input from layer 6 neurons is required for image- forming RGC axons to target the dLGN}

We found that image-forming axons fail to project to the dLGN in mice that develop without a visual cortex (Tra $2 \beta \mathrm{cKO})$ and are also diminished in mice that lack layer 6 projections to the thalamus (Tbr1 KO). This lack of targeting can be detected as early as $\mathrm{P} 2$ and is maintained into adulthood, suggesting that recognition of a target rather than the maintenance of innervation is perturbed in these mice. We do not think that the targeting defect is due to the loss of RGCs or target cells in Tra $2 \beta$ cKO mice because we did not find a decrease in RGC numbers in the retina, nor did we detect patterning defects in the mutant retina or thalamus. We also found that Isl2-GFP RGC axons that normally project to the SC and dLGN now bypass the dLGN and only target the SC. Together, our work leads to the hypothesis that cortical layer 6 axons provide an activity during development that is required for RGC axons to branch and/or terminate within the dLGN.

These findings are somewhat counterintuitive to the idea that RGC axons promote dLGN innervation by cortical layer 6 axons (Brooks et al., 2013). Fox, Guido, and colleagues used the Golli$\tau$-GFP mouse, which expresses GFP in layer 6 axons (Jacobs et al.,
2007), to show that layer 6 axons initially pause at the medial shell of the dLGN at P2, begin to innervate the dLGN at P4, and fill the entire dLGN by P14 (Seabrook et al., 2013). During this time, RGC axons innervate the dLGN. Removal of RGC inputs accelerates the timing of cortical innervation, as does the degradation of Aggrecan, a repulsive chondroitin sulfate proteoglycan expressed in early postnatal dLGN (Brooks et al., 2013; Seabrook et al., 2013). These results suggest that RGC innervation plays a critical role in the timing of cortical axon invasion into the dLGN. However, they do not predict that cortical axons are required for retinal axons targeting the dLGN, because most of these axons are not in the dLGN at the time of targeting. To reconcile these differences we propose a model whereby the small amount of cortical fibers present in the dLGN at early postnatal stages when RGC axons converge, or factors secreted from the cortical axons located at the border of the medial thalamus, are providing an activity used to promote RGC axon branching from the optic tract. This activity could be used to remove a repellent molecule found in the dLGN, similar to that proposed for Aggrecan, or be used to attract axons or promote selective adhesion as is proposed in non-image-forming areas for Reelin (IGL targeting), contactin/APP (NOT targeting), and Sema6A/Npl (MTN targeting; Su et al., 2011; Osterhout et al., 2015; Sun et al., 2015). However, in each of the above instances, the targeting activity is located in the RGC axons and the target cells. Therefore, our work reveals a 
novel mechanism that is used to deliver a target-matching cue through the axons of a third party.

\section{Development of a cortex has little contribution to the visual response properties of superficial SC neurons}

Neurons in the superficial SC receive inputs from both RGCs and layer 5 neurons in the visual cortex (Dräger and Hubel, 1975; Chandrasekaran et al., 2007). SC neurons have many distinct visual response properties including ON, OFF, ON-OFF, direction selective, and orientation selective responses (Wang et al., 2010). The contribution of layer 5 inputs to the receptive field properties of collicular neurons has been tested in animals that have had cortical ablations, cortical cooling, or light induced silencing with mixed results; some fail to show a large effect on the receptive field properties, whereas others only show that they participate in the gain of the responses (Ogasawara et al., 1984). These results can potentially be explained by the state of the animal, the severity of the lesion, or the visual stimulus presented (Zhao et al., 2014). In each of these previous experiments, the cortex was manipulated in the adult animal after the connectivity between the cortex and the SC had been established. Consistent with results from Zhao et al. (2014), in which optogenetics were used to silence V1 inputs to the SC, we find that lack of a cortex during development has very little effect on the circuitry that creates ON, OFF, direction-selective or orientation-selective SC neurons that respond to spots or drifting grating stimuli. We did find that the proportions of ON, OFF, and ON-OFF SC neurons were slightly but significantly $(p<0.01)$ different between control and Tra $2 \beta \mathrm{cKO}$ mice in our recordings providing impetus for future studies to comprehensively characterize the SC neurons response properties in cortex-less mice.

\section{Visually-evoked behaviors of Tra $2 \beta$ cKO mice remain intact}

Our results show that developing without a cortex does not dramatically affect the ability of mice to respond to light, as assayed by their performance in four different tasks. We found that $\operatorname{Tra} 2 \beta$ cKO mice have a normal pupillary light reflex, have normal light/ dark activity cycles, can associate a shock with a visual cue, and can use a visual cue to find a hidden platform. The first three tasks are thought to involve RGC axonal input into the OPN, SCN, and $S C$ respectively, and RGC targeting to these areas remains normal in the Tra $2 \beta$ cKO mice (Trejo et al., 1984; Shang et al., 2015). Rodents with a bilateral V1 lesion have shown diminished acuity in the hidden platform task (Prusky and Douglas, 2004); however, in our experiments, Tra2 $\beta$ cKO mice can learn to find a visual cue. This suggests that the visual system is plastic, and that developing without a cortex may be lead to compensatory mechanisms that enable subcortical visual circuitry to direct object recognition tasks, or that RGC innervation within the SC alone is enough to drive these visually dependent behaviors. Therefore, the Tra2 $\beta$ cKO mice may act like humans with bilateral V1 lesions; such people have the ability to detect and discriminate visual stimuli that they cannot consciously recognize (Stoerig and Cowey, 1997). Future studies aimed to characterize the visual acuity and perception of $\operatorname{Tra} 2 \beta$ cKO mice are needed to fully understand how the cortex, thalamus, and SC coordinate to achieve perception and behavior.

\section{References}

Brooks JM, Su J, Levy C, Wang JS, Seabrook TA, Guido W, Fox MA (2013) A molecular mechanism regulating the timing of corticogeniculate innervation. Cell Rep 5:573-581. CrossRef Medline

Bulfone A, Wang F, Hevner R, Anderson S, Cutforth T, Chen S, Meneses J,
Pedersen R, Axel R, Rubenstein JL (1998) An olfactory sensory map develops in the absence of normal projection neurons or GABAergic interneurons. Neuron 21:1273-1282. CrossRef Medline

Chandrasekaran AR, Shah RD, Crair MC (2007) Developmental homeostasis of mouse retinocollicular synapses. J Neurosci 27:1746-1755. CrossRef Medline

Chen SK, Badea TC, Hattar S (2011) Photoentrainment and pupillary light reflex are mediated by distinct populations of ipRGCs. Nature 476:92-95. CrossRef Medline

Cosenza RM, Moore RY (1984) Afferent connections of the ventral lateral geniculate nucleus in the rat: an HRP study. Brain Res 310:367-370. CrossRef Medline

Dhande OS, Estevez ME, Quattrochi LE, El-Danaf RN, Nguyen PL, Berson DM, Huberman AD (2013) Genetic dissection of retinal inputs to brainstem nuclei controlling image stabilization. J Neurosci 33:17797-17813. CrossRef Medline

Dhande OS, Huberman AD (2014) Retinal ganglion cell maps in the brain: implications for visual processing. Curr Opin Neurobiol 24:133-142. CrossRef Medline

Dombeck DA, Khabbaz AN, Collman F, Adelman TL, Tank DW (2007) Imaging large-scale neural activity with cellular resolution in awake, mobile mice. Neuron 56:43-57. CrossRef Medline

Dräger UC, Hubel DH (1975) Responses to visual stimulation and relationship between visual, auditory, and somatosensory inputs in mouse superior colliculus. J Neurophysiol 38:690-713. Medline

Du J, Blanche TJ, Harrison RR, Lester HA, Masmanidis SC (2011) Multiplexed, high density electrophysiology with nanofabricated neural probes. PLoS One 6:e26204. CrossRef Medline

Erişir A, Van Horn SC, Sherman SM (1997) Relative numbers of cortical and brainstem inputs to the lateral geniculate nucleus. Proc Natl Acad Sci U S A 94:1517-1520. CrossRef Medline

Feldheim DA, Vanderhaeghen P, Hansen MJ, Frisén J, Lu Q, Barbacid M, Flanagan JG (1998) Topographic guidance labels in a sensory projection to the forebrain. Neuron 21:1303-1313. CrossRef Medline

Fraley C, Raftery AE (1998) How many clusters? Which clustering method? Answers via model-based cluster analysis. Comput J 41:578-588. CrossRef

Gorski JA, Talley T, Qiu M, Puelles L, Rubenstein JL, Jones KR (2002) Cortical excitatory neurons and glia, but not GABAergic neurons, are produced in the Emx1-expressing lineage. J Neurosci 22:6309-6314. Medline

Harrington ME (1997) The ventral lateral geniculate nucleus and the intergeniculate leaflet: interrelated structures in the visual and circadian systems. Neurosci Biobehav Rev 21:705-727. CrossRef Medline

Harvey CD, Collman F, Dombeck DA, Tank DW (2009) Intracellular dynamics of hippocampal place cells during virtual navigation. Nature 461: 941-946. CrossRef Medline

Hattar S, Liao HW, Takao M, Berson DM, Yau KW (2002) Melanopsincontaining retinal ganglion cells: architecture, projections, and intrinsic photosensitivity. Science 295:1065-1070. CrossRef Medline

Hevner RF, Shi L, Justice N, Hsueh Y, Sheng M, Smiga S, Bulfone A, Goffinet AM, Campagnoni AT, Rubenstein JL (2001) Tbrl regulates differentiation of the preplate and layer 6. Neuron 29:353-366. CrossRef Medline

Jacobs EC, Campagnoni C, Kampf K, Reyes SD, Kalra V, Handley V, Xie YY, Hong-Hu Y, Spreur V, Fisher RS, Campagnoni AT (2007) Visualization of corticofugal projections during early cortical development in a $\tau$-GFPtransgenic mouse. Eur J Neurosci 25:17-30. CrossRef Medline

Kádár A, Wittmann G, Liposits Z, Fekete C (2009) Improved method for combination of immunocytochemistry and nissl staining. J Neurosci Methods 184:115-118. CrossRef Medline

Kana RK, Libero LE, Moore MS (2011) Disrupted cortical connectivity theory as an explanatory model for autism spectrum disorders. Phys Life Rev 8:410-437. CrossRef Medline

Litke AM, Bezayiff N, Chichilnisky EJ, Cunningham W, Dabrowski W, Grillo AA, Grivich M, Grybos P, Hottowy P, Kachiguine S, Kalmar RS, Mathieson K, Petrusca D, Rahman M, Sher A (2004) What does the eye tell the brain?: Development of a system for the large-scale recording of retinal output activity. IEEE Trans Nucl Sci 51:1434-1440. CrossRef

Masland RH (2012) The neuronal organization of the retina. Neuron 76: 266-280. CrossRef Medline

McKenna WL, Betancourt J, Larkin KA, Abrams B, Guo C, Rubenstein JL, Chen B (2011) Tbr1 and Fezf2 regulate alternate corticofugal neuronal identities during neocortical development. J Neurosci 31:549-564. CrossRef Medline

Mende Y, Jakubik M, Riessland M, Schoenen F, Rossbach K, Kleinridders A, Köhler C, Buch T, Wirth B (2010) Deficiency of the splicing factor 
Sfrs10 results in early embryonic lethality in mice and has no impact on full-length SMN/Smn splicing. Hum Mol Genet 19:2154-2167. CrossRef Medline

Morin LP, Allen CN (2006) The circadian visual system, 2005. Brain Res Rev 51:1-60. CrossRef Medline

Morin LP, Blanchard JH, Provencio I (2003) Retinal ganglion cell projections to the hamster suprachiasmatic nucleus, intergeniculate leaflet, and visual midbrain: bifurcation and melanopsin immunoreactivity. J Comp Neurol 465:401-416. CrossRef Medline

Niell CM, Stryker MP (2008) Highly selective receptive fields in mouse visual cortex. J Neurosci 28:7520-7536. CrossRef Medline

Niell CM, Stryker MP (2010) Modulation of visual responses by behavioral state in mouse visual cortex. Neuron 65:472-479. CrossRef Medline

Ogasawara K, McHaffie JG, Stein BE (1984) Two visual corticotectal systems in cat. J Neurophysiol 52:1226-1245. Medline

Osterhout JA, Josten N, Yamada J, Pan F, Wu SW, Nguyen PL, Panagiotakos G, Inoue YU, Egusa SF, Volgyi B, Inoue T, Bloomfield SA, Barres BA, Berson DM, Feldheim DA, Huberman AD (2011) Cadherin-6 mediates axon-target matching in a non-image-forming visual circuit. Neuron 71: 632-639. CrossRef Medline

Osterhout JA, Stafford BK, Nguyen PL, Yoshihara Y, Huberman AD (2015) Contactin-4 mediates axon-target specificity and functional development of the accessory optic system. Neuron 86:985-999. CrossRef Medline

Pfeiffenberger C, Cutforth T, Woods G, Yamada J, Rentería RC, Copenhagen DR, Flanagan JG, Feldheim DA (2005) Ephrin-As and neural activity are required for eye-specific patterning during retinogeniculate mapping. Nat Neurosci 8:1022-1027. CrossRef Medline

Prusky GT, Douglas RM (2004) Characterization of mouse cortical spatial vision. Vis Res 44:3411-3418. CrossRef Medline

Quina LA, Pak W, Lanier J, Banwait P, Gratwick K, Liu Y, Velasquez T, O'Leary DD, Goulding M, Turner EE (2005) Brn3a-expressing retinal ganglion cells project specifically to thalamocortical and collicular visual pathways. J Neurosci 25:11595-11604. CrossRef Medline

Rashid T, Upton AL, Blentic A, Ciossek T, Knöll B, Thompson ID, Drescher U (2005) Opposing gradients of ephrin-As and EphA7 in the superior colliculus are essential for topographic mapping in the mammalian visual system. Neuron 47:57-69. CrossRef Medline

Roberts JM, Ennajdaoui H, Edmondson C, Wirth B, Sanford JR, Chen B (2014) Splicing factor TRA2B is required for neural progenitor survival. J Comp Neurol 522:372-392. CrossRef Medline

Schmidt TM, Chen SK, Hattar S (2011) Intrinsically photosensitive retinal ganglion cells: many subtypes, diverse functions. Trends Neurosci 34: 572-580. CrossRef Medline

Schmitzer-Torbert N, Jackson J, Henze D, Harris K, Redish AD (2005) Quantitative measures of cluster quality for use in extracellular recordings. Neuroscience 131:1-11. CrossRef Medline

Seabrook TA, El-Danaf RN, Krahe TE, Fox MA, Guido W (2013) Retinal input regulates the timing of corticogeniculate innervation. J Neurosci 33:10085-10097. CrossRef Medline

Shang C, Liu Z, Chen Z, Shi Y, Wang Q, Liu S, Li D, Cao P (2015) A parvalbumin-positive excitatory visual pathway to trigger fear responses in mice. Science 348:1472-1477. CrossRef Medline
Shatz CJ, Rakic P (1981) The genesis of efferent connections from the visual cortex of the fetal rhesus monkey. J Comp Neurol 196:287-307. CrossRef Medline

Sillito AM, Cudeiro J, Jones HE (2006) Always returning: feedback and sensory processing in visual cortex and thalamus. Trends Neurosci 29: 307-316. CrossRef Medline

Stoerig P, Cowey A (1997) Blindsight in man and monkey. Brain 120: 535-559. CrossRef Medline

Su J, Haner CV, Imbery TE, Brooks JM, Morhardt DR, Gorse K, Guido W, FoxMA (2011) Reelin is required for class-specific retinogeniculate targeting. J Neurosci 31:575-586. CrossRef Medline

Sun LO, Brady CM, Cahill H, Al-Khindi T, Sakuta H, Dhande OS, Noda M, Huberman AD, Nathans J, Kolodkin AL (2015) Functional assembly of accessory optic system circuitry critical for compensatory eye movements. Neuron 86:971-984. CrossRef Medline

Sweeney NT, Tierney H, Feldheim DA (2014) Tbr2 is required to generate a neural circuit mediating the pupillary light reflex. J Neurosci 34:54475453. CrossRef Medline

Theyel BB, Llano DA, Sherman SM (2010) The corticothalamocortical circuit drives higher-order cortex in the mouse. Nat Neurosci 13:84-88. CrossRef Medline

Trejo LJ, Cicerone CM (1984) Cells in the pretectal olivary nucleus are in the pathway for the direct light reflex of the pupil in the rat. Brain Res 300: 49-62. CrossRef Medline

Triplett JW, Phan A, Yamada J, Feldheim DA (2012) Alignment of multimodal sensory input in the superior colliculus through a gradientmatching mechanism. J Neurosci 32:5264-5271. CrossRef Medline

Triplett JW, Wei W, Gonzalez C, Sweeney NT, Huberman AD, Feller MB, Feldheim DA (2014) Dendritic and axonal targeting patterns of a genetically-specified class of retinal ganglion cells that participate in image-forming circuits. Neural Dev 9:2. CrossRef Medline

Tye C, Bolton P (2013) Neural connectivity abnormalities in autism: insights from the tuberous sclerosis model. BMC Med 11:55. CrossRef Medline

Vorhees CV, Williams MT (2006) Morris water maze: procedures for assessing spatial and related forms of learning and memory. Nat Protoc 1:848-858. CrossRef Medline

Wang L, Sarnaik R, Rangarajan K, Liu X, Cang J (2010) Visual receptive field properties of neurons in the superficial superior colliculus of the mouse. J Neurosci 30:16573-16584. CrossRef Medline

Wang Q, Burkhalter A (2013) Stream-related preferences of inputs to the superior colliculus from areas of dorsal and ventral streams of mouse visual cortex. J Neurosci 33:1696-1705. CrossRef Medline

Wässle H (2004) Parallel processing in the mammalian retina. Nat Rev Neurosci 5:747-757. CrossRef Medline

Wiltschko AB, Gage GJ, Berke JD (2008) Wavelet filtering before spike detection preserves waveform shape and enhances single-unit discrimination. J Neurosci Methods 173:34-40. CrossRef Medline

Zhao X, Liu M, Cang J (2014) Visual cortex modulates the magnitude but not the selectivity of looming-evoked responses in the superior colliculus of awake mice. Neuron 84:202-213. CrossRef Medline 